\title{
Covert Shifts of Spatial Attention in the Macaque Monkey
}

\author{
(CNatalie Caspari, ${ }^{1,5}$ Thomas Janssens, ${ }^{1}$-Dante Mantini, ${ }^{1,2,3}$-Rik Vandenberghe, ${ }^{4,5}$ and $\odot W i m$ Vanduffel ${ }^{1,6,7}$ \\ ${ }^{1}$ Laboratory for Neuro-and Psychophysiology, KU Leuven Medical School, 3000 Leuven, Belgium, ${ }^{2}$ Department of Health Sciences and Technology, ETH \\ Zurich, 8057 Zurich, Switzerland, ${ }^{3}$ Department of Experimental Psychology, University of Oxford, OX1 3UD Oxford, United Kingdom, ${ }^{4}$ Neurology \\ Department, University Hospitals Leuven, 3000 Leuven, Belgium, ${ }^{5}$ Laboratory for Cognitive Neurology, Neurosciences Department, KU Leuven, 3000 \\ Leuven, Belgium, ${ }^{6}$ Harvard Medical School, Boston, Massachusetts 02115, and ${ }^{7} \mathrm{MGH}$ Martinos Center for Biomedical Imaging, Charlestown, Massachusetts \\ 02129
}

In the awake state, shifts of spatial attention alternate with periods of sustained attention at a fixed location or object. Human fMRI experiments revealed the critical role of the superior parietal lobule (SPL) in shifting spatial attention, a finding not predicted by human lesion studies and monkey electrophysiology. To investigate whether a potential homolog of the human SPL shifting region exists in monkeys (Macaca mulatta), we adopted an event-related fMRI paradigm that closely resembled a human experiment (Molenberghs et al., 2007). In this paradigm, a pair of relevant and irrelevant shapes was continuously present on the horizontal meridian. Subjects had to covertly detect a dimming of the relevant shape while ignoring the irrelevant dimmings. The events of interest consisted of the replacement of one stimulus pair by the next. During shift but not stay events, the relevant shape of the new pair appeared at the contralateral position relative to the previous one. Spatial shifting events activated parietal areas V6/V6A and medial intraparietal area, caudo-dorsal visual areas, the most posterior portion of the superior temporal sulcus, and several smaller frontal areas. These areas were not activated during passive stimulation with the same sensory stimuli. During stay events, strong direction-sensitive attention signals were observed in a distributed set of contralateral visual, temporal, parietal, and lateral prefrontal areas, the vast majority overlapping with the sensory stimulus representation. We suggest medial intraparietal area and V6/V6A as functional counterparts of human SPL because they contained the most widespread shift signals in the absence of contralateral stay activity, resembling the functional characteristics of the human SPL shifting area.

Key words: fMRI; human; monkey; shifting; spatial attention; superior parietal lobe

\section{Introduction}

Shifts in spatial attention are essential for visual selection and goal-driven behavior. In humans, a portion of the medial superior parietal lobule (SPL) is consistently activated during both overt and covert spatial attention shifts (Vandenberghe et al., 2001; Yantis et al., 2002; Molenberghs et al., 2007; Kelley et al., 2008). Specifically, whenever humans shift attention between locations (Yantis et al., 2002), objects (Serences et al., 2004), features (Liu et al., 2003), modalities (Shomstein and Yantis, 2004),

Received 0ct. 21, 2014; revised March 21, 2015; accepted March 27, 2015.

Author contributions: R.V. and W.V. designed research; N.C. performed research; T.J. and D.M. contributed unpublished reagents/analytic tools; N.C. analyzed data; N.C., R.V., and W.V. wrote the paper.

This work was supported by Inter-University Attraction Pole 7/11, the Research Foundation Flanders (senior clinical investigator Grant to R.V.; and G0660.09, G0A09.13, G083111.10, G0A5613, G.062208.10, and Odysseus G0007.12) to W.V.; KU Leuven (0T/12/097; Programme Financing PFV/10/008; Impuls financiering Zware Apparatuur); and Hercules to W.V., D.M. holds a Sir Henry Dale Fellowship jointly funded by the Wellcome Trust and the Royal Society (Grant 101253/Z/13/Z). We thank A. Coeman, C. Fransen, P. Kayenbergh, I. Puttemans, S. De Pril, G. Meulemans, and C. Van Eupen for technical support and S. Raiguel for his comments on the manuscript.

The authors declare no competing financial interests.

This article is freely available online through the J Neurosci Author Open Choice option.

Correspondence should be addressed to Dr. Wim Vanduffel, Harvard Medical School, 25 Shattuck Street, Boston, Massachusetts 02115. E-mail: wim@nmr.mgh.harvard.edu.

D0l:10.1523/JNEUROSCI.4383-14.2015

Copyright $\odot 2015$ Caspari et al.

This is an Open Access article distributed under the terms of the Creative Commons Attribution License Creative Commons Attribution 4.0 International, which permits unrestricted use, distribution and reproduction in any medium provided that the original work is properly attributed. or even task sets (Chiu and Yantis, 2009; Esterman et al., 2009), this region in medial superior posterior parietal cortex becomes transiently activated. On the other hand, the human intraparietal sulcus (IPS) is engaged whenever subjects have to recalibrate the attentional weights of perceptual units, whether or not this results in a spatial attention shift (Molenberghs et al., 2008; Vandenberghe et al., 2012). Causal evidence for such functional segregation between SPL and IPS comes from transcranial magnetic stimulation (TMS) studies showing that inactivation of SPL selectively impaired target discrimination immediately after an attention shift, regardless of shift direction, whereas TMS of ventral IPS affected target discrimination at contralateral locations only (Capotosto et al., 2013).

Monkey electrophysiology studies have shown the engagement of lateral intraparietal area (LIP) (Bisley and Goldberg, 2003a) and frontal eye fields (FEFs) (Thompson et al., 1997; Wardak et al., 2006, 2011; Buschman and Miller, 2009) during covert spatial attention shifts. These areas, however, also compute strong direction-dependent attention signals (Latto and Cowey, 1971; Li et al., 1999), as confirmed by fMRI (Kagan et al., 2010; Patel et al., 2010). In addition, Galletti et al. (2010) have provided evidence for modulation of neuronal activity in area V6A during covert spatial attention shifts, but this activity was not dissociated from sensory events or the monkey's operant behavior. Finally, prefrontal area 46 and anterior cingulate cortex 
(ACC) showed early onset single-cell activity in the context of attention shifts (Kaping et al., 2011). All aforementioned monkey areas, however, differ substantially in location or function from human SPL. Thus, it remains an unanswered question whether monkey cortex contains any region functionally homologous to human SPL as previously characterized by fMRI (Vandenberghe et al., 2001; Yantis et al., 2002).

Our goal was to identify monkey brain regions involved in covert spatial attention shifts. Also, we sought to identify regions involved in sustained contralateral attention and to map the spatial relationship between these two attentional signals and the sensory stimulus representation. We trained monkeys to covertly shift attention whenever a relevant shape changed location. This task was similar to the human fMRI task previously used to isolate effects of transient spatial attention shifts against a sustained-attention baseline (Molenberghs et al., 2007). Cue events probing the monkey's allocation of attention occurred independently of the events of interest (i.e., shift and stay events when one stimulus pair was replaced by the next). The cue events consisted of a dimming of relevant shapes while dimming of irrelevant shapes had to be ignored. Hence, we could dissociate attentional shifting operations from stimulus changes, sustained attention effects and processes engaged during target detection, response preparation, and execution.

\section{Materials and Methods}

Subjects. Three rhesus monkeys (female M13, female M24 and male M35; Macaca mulatta; 3-6 kg; 3-9 years of age) participated in the experiments. Animal care and experimental procedures were performed in accordance with the National Institute of Health's Guide for the Care and Use of Laboratory Animals, the European legislation (Directive 2010/63/EU), and were approved by the Ethical Committee at the KU Leuven. The details of the general fMRI procedures and training of monkeys have been described previously (Vanduffel et al., 2001; Nelissen et al., 2005).

Stimuli and tasks: spatial shift experiment. The experimental paradigm was adapted from a human fMRI experiment (Molenberghs et al., 2007). Two stimuli were placed on the horizontal meridian at 9.25 degrees eccentricity, in the left and right hemifields (Fig. 1, I). All stimuli were white on a black background and of equal area $\left(1.59\right.$ degrees $\left.^{2}\right)$. There were two possible coupled stimulus pairs: a square with a triangle and a circle with a diamond. Each pair contained a relevant and an irrelevant stimulus. To obtain a reward, the monkey had to respond by manually interrupting a light beam when the relevant (Fig. 1, IVa), but not when
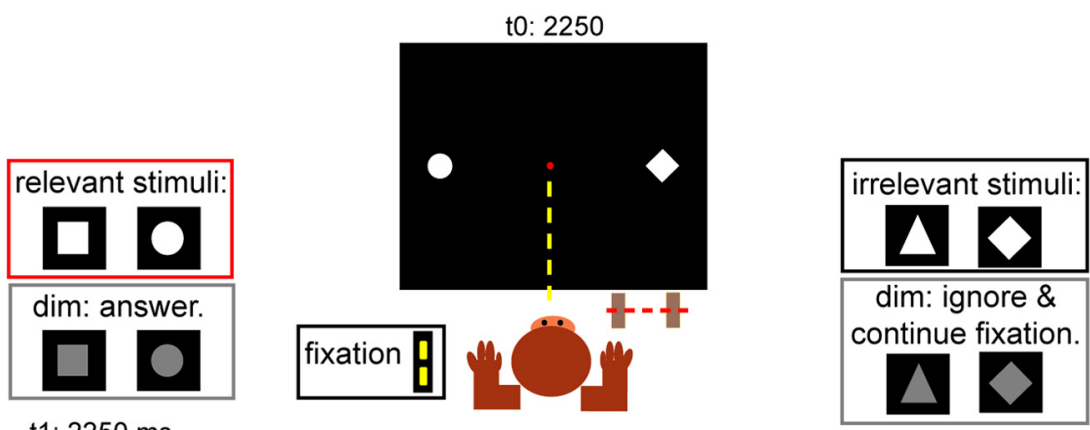

$\mathrm{t} 1: 2250 \mathrm{~ms}$
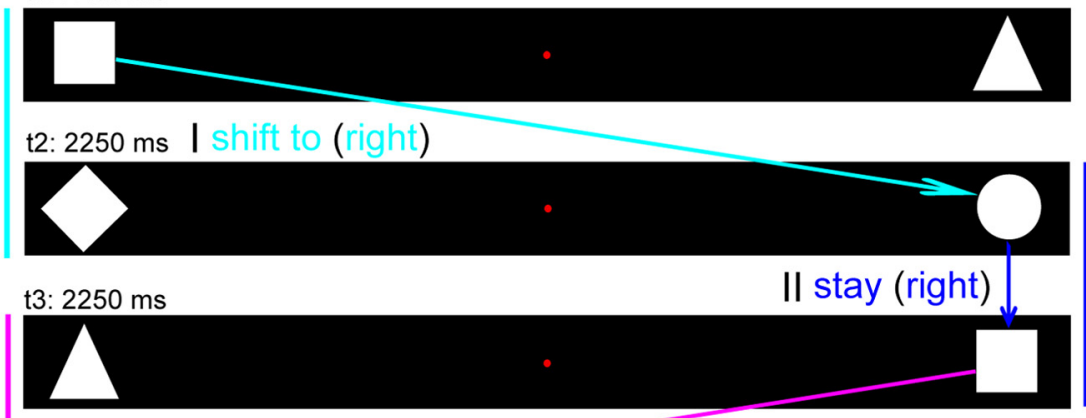

t4: 50- 1500 III shift (to left)
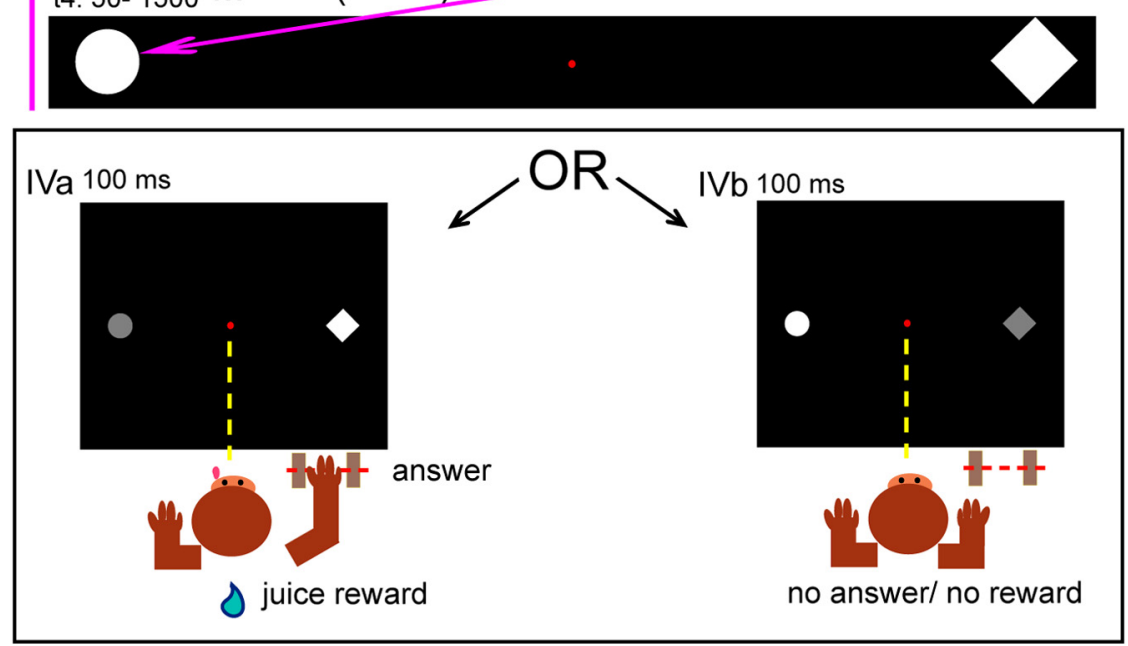

t4: $2100-650$

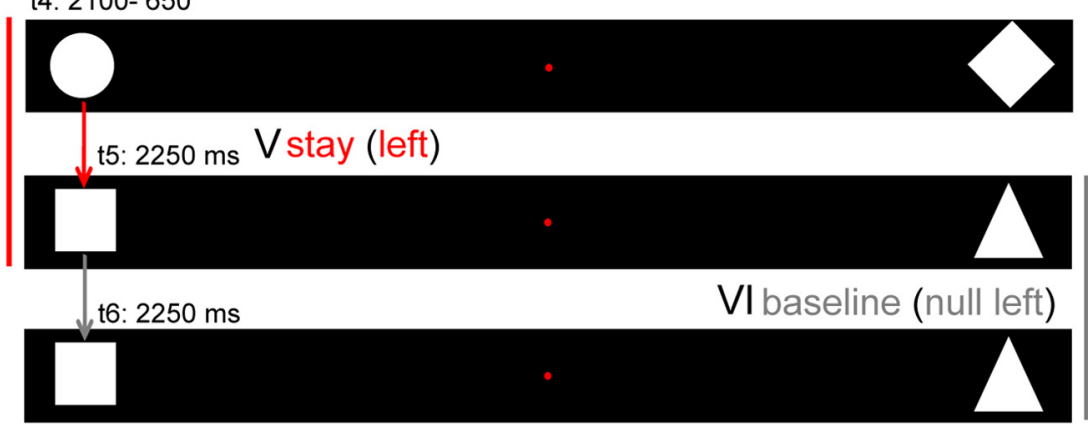

tn: $2250 \mathrm{~ms}$

Figure 1. Stimuliand task. Top (schematic of display viewed by the monkey), Animals fixated during all trial types, also when responding to dimming events. One stimulus pair (consisting of a relevant and irrelevant shape) was presented at any given time that the monkey fixated. Each pair was replaced, with no temporal gap, by the succeeding pair after $2250 \mathrm{~ms}$. Top left, Dimming of the relevant shapes had to be indicated by a manual response to receive a juice reward. Top right, Dimming of the irrelevant shapes had to be ignored. Examples of different event types: I, shift right, a feature change cues the monkey to make a covert spatial-attention shift to the right hemifield (the left relevant stimulus [square] is replaced by an irrelevant one [diamond]); II, stay right, a feature change cues the animal to maintain its covert attention to the right because the relevant stimulus (square) of the next pair appears at the same position as the preceding one (circle); III, shift left; IVa, a relevant dimming, the monkey responds and is rewarded; IVb, irrelevant dimming, the monkey continues fixating, no reward is given; $V$, stay left; and VI, null left, same shapes remain at the same position for $2 \times 2250 \mathrm{~ms}$. 
Table 1. Dimming of the irrelevant stimulus ${ }^{a}$

\begin{tabular}{|c|c|c|c|c|c|c|c|}
\hline Monkey & Null left & Null right & Stay left & Stay right & Shift left & Shift right & Wilcoxon singed rank test \\
\hline \multicolumn{8}{|l|}{ M13 } \\
\hline Mean & 0.00 & 0.58 & 0.00 & 0.19 & 0.00 & 0.00 & \multirow[t]{2}{*}{$p=0.5-1.0$ for all conditions } \\
\hline SD & 0.00 & 1.39 & 0.00 & 0.56 & 0.00 & 0.00 & \\
\hline \multicolumn{8}{|l|}{ M24 } \\
\hline Mean & 0.16 & 0.81 & 0.15 & 0.59 & 0.40 & 0.86 & \multirow[t]{2}{*}{$p=0.06-1.0$ for all conditions } \\
\hline SD & 0.37 & 1.06 & 0.53 & 0.93 & 0.97 & 1.16 & \\
\hline \multicolumn{8}{|l|}{ M35 } \\
\hline Mean & 0.11 & 0.00 & 0.13 & 0.00 & 0.00 & 0.13 & \multirow[t]{2}{*}{$p=\sim 1.0$ for all conditions } \\
\hline SD & 0.36 & 0.00 & 0.40 & 0.00 & 0.00 & 0.40 & \\
\hline
\end{tabular}

a Dimming of irrelevant stimulus (fixation trial, no response): \% false alarms of total irrelevant dimming and standard deviations (SD). $p$ (Wilcoxon signed-rank test for zero medians).

Table 2. Dimming of the relevant stimulus ${ }^{a}$

\begin{tabular}{|c|c|c|c|c|c|c|c|c|c|}
\hline & \multirow[b]{2}{*}{ Monkey } & \multirow[b]{2}{*}{ Null left } & \multirow[b]{2}{*}{ Null right } & \multirow[b]{2}{*}{ Stay left } & \multirow[b]{2}{*}{ Stay right } & \multirow[b]{2}{*}{ Shift left } & \multirow[b]{2}{*}{ Shift right } & \multicolumn{2}{|c|}{ Repeated-measures ANOVA $3 \times 2$} \\
\hline & & & & & & & & Condition (null, stay, shift) & Direction (left, right) \\
\hline \multirow[t]{9}{*}{ Reaction times (ms) } & M13 & & & & & & & & \\
\hline & Mean & 360.96 & 341.89 & 377.22 & 349.42 & 354.92 & 324.55 & $F_{(2,16)}=2.95$ & $F_{(1,8)}=9.16$ \\
\hline & SD & 32.86 & 20.87 & 37.53 & 36.95 & 30.35 & 22.38 & $p=0.08$ & $p=0.02$ \\
\hline & M24 & & & & & & & & \\
\hline & Mean & 399.92 & 405.13 & 404.46 & 398.59 & 410.62 & 393.91 & $F_{(2,22)}=0.051$ & $F_{(1,11)}=2.12$ \\
\hline & $S D$ & 23.26 & 37.24 & 23.35 & 32.10 & 33.79 & 33.79 & $p=0.95$ & $p=0.17$ \\
\hline & M35 & & & & & & & & \\
\hline & Mean & 498.27 & 503.75 & 490.18 & 495.19 & 488.61 & 496.05 & $F_{(2,18)}=3.41$ & $F_{(1,9)}=4.89$ \\
\hline & $S D$ & 18.70 & 17.64 & 18.69 & 22.81 & 22.12 & 26.47 & $p=0.06$ & $p=0.05$ \\
\hline \multirow[t]{9}{*}{$\%$ hit } & M13 & & & & & & & & \\
\hline & Mean & 45.20 & 67.48 & 56.67 & 69.30 & 49.48 & 68.62 & $F_{(2,16)}=2.63$ & $F_{(1,8)}=31.37$ \\
\hline & $S D$ & 6.61 & 5.59 & 16.07 & 9.38 & 7.96 & 11.09 & $p=0.10$ & $p=0.0005$ \\
\hline & M24 & & & & & & & & \\
\hline & Mean & 83.05 & 87.97 & 83.53 & 83.98 & 86.33 & 86.39 & $F_{(2,22)}=1.93$ & $F_{(1,11)}=1.06$ \\
\hline & $S D$ & 5.05 & 4.85 & 4.11 & 5.74 & 7.11 & 4.93 & $p=0.17$ & $p=0.33$ \\
\hline & M35 & & & & & & & & \\
\hline & Mean & 84.57 & 80.64 & 87.28 & 81.29 & 86.74 & 85.00 & $F_{(2,18)}=1.71$ & $F_{(1,9)}=8.28$ \\
\hline & $S D$ & 6.36 & 5.12 & 4.41 & 6.10 & 3.15 & 5.51 & $p=0.21$ & $p=0.02$ \\
\hline \multirow[t]{9}{*}{$\%$ miss } & M13 & & & & & & & & \\
\hline & Mean & 4.52 & 2.67 & 2.37 & 1.21 & 3.51 & 2.17 & $F_{(2,16)}=1.10$ & $F_{(1,8)}=2.31$ \\
\hline & SD & 4.70 & 3.28 & 4.27 & 1.84 & 4.59 & 3.66 & $p=0.36$ & $p=0.17$ \\
\hline & M24 & & & & & & & & \\
\hline & Mean & 11.21 & 8.26 & 10.45 & 11.17 & 8.53 & 10.99 & $F_{(2,22)}=0.47$ & $F_{(1,11)}=0.01$ \\
\hline & SD & 3.01 & 3.26 & 4.37 & 4.67 & 4.83 & 5.94 & $p \stackrel{p .63}{=} 0.63$ & $p=0.94$ \\
\hline & M35 & & & & & & & & \\
\hline & Mean & 11.42 & 13.79 & 9.67 & 12.26 & 11.00 & 11.83 & $F_{(2,18)}=0.66$ & $F_{(1,9)}=3.19$ \\
\hline & SD & 4.74 & 5.67 & 3.57 & 3.26 & 3.33 & 4.71 & $p=0.53$ & $p=0.11$ \\
\hline
\end{tabular}

${ }^{a}$ Dimming of relevant stimulus (response trial): mean and standard deviation (SD) are shown for reaction times, hits, and misses. Percent hits (\% hit) of total relevant dimmings per condition. Percent missed dimmings (\% misses) of total relevant dimmings. None of the interactions of Repeated-measures ANOVAS was significant; therefore, data are not shown.

the irrelevant-stimulus dimmed (Fig. 1, IVb). Monkeys were intensively trained ( $>4$ months) to attend only the relevant stimulus of each pair and to fixate upon the central fixation point during the entire task. Fixationonly trials were not rewarded. Relevant stimuli were identical for M13 and M35 (square and circle) and swapped for M24 (triangle and diamond). Monkeys thus covertly maintained their attentional focus at the location of the relevant stimuli. Compliance was probed by the occasional randomly inserted dimming events (the relevant and irrelevant shapes dimmed for $100 \mathrm{~ms}$ in $14 \%$ of the trials each). Luminance contrast (gray level) was adapted on a run-wise basis to approximate a performance level of $\sim 85 \%-90 \%$ uninterrupted, correctly performed trials, to avoid ceiling levels in behavioral performance.

The sustained attention baseline was transiently interrupted by two types of events. These consisted of a replacement (without temporal gaps) of one stimulus pair by the second stimulus pair, occupying the same positions. In the first event type (Fig. 1, I, III), the relevant stimulus of the new pair appeared at the position previously occupied by the irrelevant stimulus of the preceding pair, and vice versa. This feature change, in combination with a positional change of the relevant stimulus, elicited a shift in spatial attention (shift event). A "shift-right" event (Fig. $1, \mathrm{I})$ corresponded to a spatial shift of the relevant stimulus from the left to the right hemifield and a "shift-left" (Fig. 1, III) to a spatial shift from right to left.

In event Type 2 (Fig. 1, II, V), the relevant stimulus of the new pair appeared at the same position as the relevant stimulus of the preceding pair. Hence, the relevant stimulus site remained unchanged, inducing no spatial shift in attention. This was called a stay event: "stay-right" (Fig. 1, II) or "stay-left" (Fig. 1, V). With this event, attention was already deployed at the target location before the feature change (event onset). One-third of all trials were null events (Fig. 1, VI, "null left"). During these events, the stimuli remained on the screen without being changed. Each run contained an equal number of shift, stay, and null events. The positions occupied by the stimuli, as well as the number of relevant and irrelevant dimming events, were matched across event types. Dimmings were equally distributed between 50 and $1500 \mathrm{~ms}$ after event onset. M13 and M24 responded in 50\% of the scan sessions with the right hand and the other half with the left hand. Because the data of interest in these two monkeys did not change as function of the hand used, M35 was trained to respond with the left hand only.

During consecutive stimulus displays, monkeys were trained to fixate on a red dot $(0.3$ degree $)$ inside a $2 \times 3$ degree fixation window while keeping their hands in the response box. The position of both hands 
within the response box was checked using infrared light beams. This procedure minimized unwanted (hand) movements or saccadic eye movements toward the peripheral stimuli. In cases where the monkeys made a hand movement (except during the dimming of the relevant stimulus) or an eye movement outside the fixation window, the trial was aborted and the stimulus display disappeared.

Stimulus localizer experiment. To characterize the cortical representation of the visual stimuli, monkeys were scanned with a fixationonly task after the main experiment. The same stimuli (square, triangle, diamond, and circle) were shown unilaterally to the left, unilaterally to the right, and bilaterally at the same positions $(9.25$ degree eccentricity) as in the main experiment. All possible stimulus combinations were displayed and replaced every $200 \mathrm{~ms}$ (without gaps), resulting in blocks of $20 \mathrm{~s}$. These three stimulation blocks were interleaved with a fourth block of $20 \mathrm{~s}$ without visual stimuli, during which only the red fixation dot was present. The monkeys fixated within a $2 \times 3$ window while their hands remained in the response box to receive a reward. The juice-reward interval was systematically decreased from 2500 to $500 \mathrm{~ms}$ to encourage long, uninterrupted fixation sequences.

fMRI acquisition: procedure. Monkeys were trained in a mockup of an MRI scanner for all tasks. They were scanned following several months $(\sim 4)$ of training, when fixation performance exceeded $90 \%-95 \%$, and when false-alarm rates were close to $0 \%$. The monkey sat in a sphinx position, head fixed to the plastic monkey chair, directly facing the screen. Eye position was monitored at $120 \mathrm{~Hz}$, using pupil position and corneal reflection (Iscan).

Scanning. Functional images were acquired with a 3.0 tesla horizontal bore full-body scanner (TIM Trio; Siemens Healthcare), using a gradient-echo $\mathrm{T} 2{ }^{\star}$-weighted echo-planar imaging-sequence: 40 horizontal slices; TR, 2 s; TE, 17 ms (M13, M24), 19 ms (M35); $1.25 \times 1.25 \times$ $1.25 \mathrm{~mm}^{3}$ isotropic voxels, image acceleration factor of 3 (M13, M24), or 2 (M35). M13 was scanned with a custom-built, 8-channel, phased-array receive coil, and a saddle-shaped, radial transmit-only surface coil (Kolster et al., 2009). M24 had been implanted with an 8-channel receive array coil on top of the skull, beneath the headpost, improving the sensitivity for MR-imaging (Janssens et al., 2012). M35 had been implanted with a 5-channel receive array coil (due to additional recording wells, only 5 coils were constructed). Scanning of M24 was performed with the same scanner, main parameters, and transmit coil as M13, but also using a $36 \mathrm{~cm}$ inner-diameter head gradient set (AC88, maximum strength: 80 $\mathrm{mT} / \mathrm{m}$; maximum slew rate: $800 \mathrm{~T} / \mathrm{m} / \mathrm{s}$ ). Slices were oriented transversally, covering the entire brain. High-resolution anatomical images were acquired for each monkey during a separate session under anesthesia, using a single radial transmit-receive surface coil and an MPRAGE sequence $(\mathrm{TR}=2200 \mathrm{~ms}$; $\mathrm{TE}=4.05 \mathrm{~ms} ; 208$ slices; $0.4 \mathrm{~mm}$ isotropic voxel size)

Before each functional scanning session, a contrast agent, monocrystalline iron oxide nanoparticle (MION) (Sinerem; Laboratoire Guerbet, or Feraheme), was injected into the femoral/saphenous vein $(6-11 \mathrm{mg} /$ $\mathrm{kg})$. Use of the contrast agent improves the contrast-noise ratio approximately threefold (Vanduffel et al., 2001; Leite et al., 2002) and enhances spatial selectivity of the MR signal changes (Zhao et al., 2006), compared with BOLD measurements. As MION measurements depend only on blood volume (Mandeville and Marota, 1999), polarity of all signal change values has been inverted (as increased brain activation produces a decrease in MR signal in MION cerebral blood volume maps).

The main experiment (spatial shifting task) was scanned using an event-related design, and a run lasted $610 \mathrm{~s}$ (305 volumes, including 4 dummy volumes). The localizer experiment, to assess the stimulus representation, was scanned with a block design with the same parameters as the main experiment, a run lasting $490 \mathrm{~s}$ ( 245 volumes, including 4 dummy volumes), as described above.

Preprocessing. The raw EPI images were corrected for the lowest-order off-resonance effects and aligned with respect to the GRE reference images before performing a SENSE image reconstruction (Pruessmann et al., 1999). Residual N/2 artifacts in the reconstructed images were removed using an algorithm based on the UNFOLD method (Madore et al., 1999) and were further corrected for higher-order distortions using a
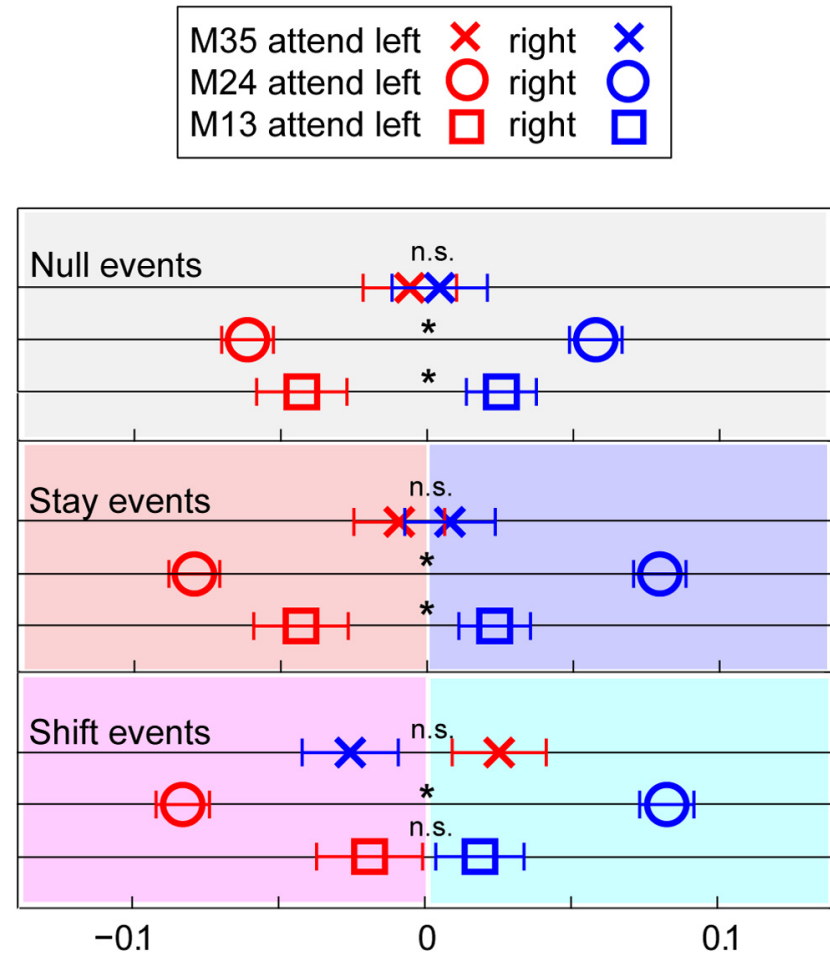

Degrees of visual angle in $\mathrm{X}$-direction

Figure 2. Behavior: eye position data. Deviation of the eye position in the x-direction normalized with respect to the center across monkeys ( 0 degrees of visual angle). Error bars indicate standard error of the mean (SEM) across trials. Squares represent M13. Circles represent M24. Crosses represent M35. Red represents null left, stay left, and shift left. Blue represents null right, stay right, and shift right. Shift events: average of data points between 301 and $600 \mathrm{~ms}$ after event onset, representing the shift arrival position. ${ }^{*} p<0.05$ (post hoc test, Fisher's least significant difference) between attention left and right. n.s., Not significant. Note the small but significant deviation of the eyes toward the attended hemifield in 2 of 3 subjects.

nonrigid slice-by-slice distortion correction (Kolster et al., 2009). Subsequent data analysis was performed using SPM5 software package (Wellcome Department of Cognitive Neurology, London) running under MATLAB (MathWorks). The preprocessing steps included the following: (1) skull-stripping the images, (2) coregistration of the anatomical and mean functional images, and (3) spatial normalization of all images to the 112-RM atlas (McLaren et al., 2009) aligned to the F99 surfacebased atlas (Van Essen et al., 2001), with a voxel size of $1 \times 1 \times 1 \mathrm{~mm}$. Images were smoothed with a $1.5 \mathrm{~mm}$ kernel.

Data analysis of main experiment (event related). As illustrated in Figure 1 (and described above), the following events entered the GLM: stay events, composed of a feature change (Fig. 1, II: stay-right, Fig. 1, V: stay-left); shift events, composed of a feature change and a spatial shift (Fig. 1, I: shift-right, Fig. 1, III: shift-left); and null events (Fig. 1, VI: null left, no feature change). An equal number of null-left and null-right events constituted the attention baseline. The number of correctly executed trials analyzed for each event type was equalized for left- and rightsided attention. Only trial sequences with at least 3 or more consecutive and correctly executed fixation trials were included in the analysis. The dimming and reward events within these series of correctly executed fixation trials were excluded from the analyses. The GLM included 5 regressors for the five conditions, 2 eye movement regressors, and 6 additional head motion regressors (translation and rotation in 3D), per run. Each condition was modeled by convolving a $\gamma$ function $(\delta=0, \tau=$ 8 , and exponent $=0.3$ ), modeling the MION hemodynamic response function, at the onset of the condition (transition of stimulus displays). The first two main contrasts of interest were stay-left versus stay-right (contrast 1 ) and vice versa (contrast 2). These delineated areas reflecting the current locus of attention and will be deemed "contralateral stay," relative to the observed hemisphere. 
Table 3. Eye data ${ }^{a}$

\begin{tabular}{|c|c|c|c|c|c|c|c|c|}
\hline \multirow[b]{2}{*}{ Monkey } & \multirow[b]{2}{*}{ Null left } & \multirow[b]{2}{*}{ Null right } & \multirow[b]{2}{*}{ Stay left } & \multirow[b]{2}{*}{ Stay right } & \multirow[b]{2}{*}{ Shift left } & \multirow[b]{2}{*}{ Shift right } & \multicolumn{2}{|c|}{ Repeated-measures ANOVA $3 \times 2$} \\
\hline & & & & & & & Condition (null, stay, shift) & Direction (left, right) \\
\hline \multicolumn{9}{|l|}{ M13 } \\
\hline Mean & -0.05 & 0.03 & -0.06 & 0.03 & -0.09 & -0.04 & $F_{(2,16)}=56.97$ & \multirow{2}{*}{$\begin{array}{l}F_{(1,8)}=6.67 \\
p=0.03\end{array}$} \\
\hline SD & 0.06 & 0.03 & 0.07 & 0.04 & 0.05 & 0.03 & $p<0.0001$ & \\
\hline \multicolumn{9}{|l|}{ M24 } \\
\hline Mean & -0.06 & 0.06 & -0.08 & 0.08 & -0.07 & 0.10 & \multirow{2}{*}{$\begin{array}{l}F_{(2,22)}=8.52 \\
p=0.0018\end{array}$} & \multirow{2}{*}{$\begin{array}{l}F_{(1,11)}=24.67 \\
p=0.0004\end{array}$} \\
\hline SD & 0.06 & 0.06 & 0.07 & 0.07 & 0.04 & 0.05 & & \\
\hline \multicolumn{9}{|l|}{ M35 } \\
\hline Mean & 0.00 & 0.00 & -0.01 & 0.01 & 0.01 & -0.04 & \multirow{2}{*}{$\begin{array}{l}F_{(2,18)}=2.21 \\
p=0.14\end{array}$} & \multirow{2}{*}{$\begin{array}{l}F_{(1,9)}=0.09 \\
p=0.78\end{array}$} \\
\hline SD & 0.03 & 0.03 & 0.06 & 0.06 & 0.04 & 0.03 & & \\
\hline
\end{tabular}

${ }^{a}$ Eye data are displayed in degrees of visual angle, representing the deviation of eye position from the midline (middle of the fixation window) and it's standard deviation (SD) across sessions, per condition/monkey. None of the interactions of Repeated-measures ANOVAS was significant; therefore, data are not shown.

Activations correlating with "transient" spatial attention shifts regardless of the direction of the shift were visualized by contrasting bilateral "shifts" versus "stay" (shift-left and shift-right vs stay-left and stay-right, contrast 3).

Data were first analyzed per subject and scanning day (session) with a fixed-effects GLM. Runs with a fixation performance $<85 \%$ were excluded. For M13, this resulted in 9 sessions with a total of 131 runs (on average 15 runs/session); for M24, 12 sessions with a total of 181 runs (on average 15 runs/session); and for M35, 10 sessions with a total of 171 runs (on average 17 runs/session) that were included in the analyses. Next, we computed a session-wise second-level mixed-effect analysis (MFX) (Friston et al., 2005), with the "con-images" of contrasts $1-3$, obtained from the first level analyses as input, including a total of 31 images per contrast: $9(\mathrm{M} 13)+12(\mathrm{M} 24)+10(\mathrm{M} 35)$ sessions. All statistical maps were based on this MFX analysis. Contralateral stay maps for contrasts 1 and 2 were thresholded at $p=0.001$, whereas shift maps (contrast 3 ) were shown at a threshold of $p=0.01$, both uncorrected. The relatively low threshold for the shifting contrast was motivated by the fact that we had a clear a priori hypothesis about superior parietal involvement.

Second, to compute raw time courses for the group, we performed a group fixed-effect analysis (FFX). This was done by selecting the best 69 runs for each animal according to behavior (percentage fixation and responseperformance), warped to group space. These 207 runs (reaching the upper limit of MATLAB memory for NIFTI files: 207 runs $\times 305$ volumes) were pooled for the FFX analysis, and the final contrasts (same as used in the MFX analysis) were thresholded at family-wise error (FWE, corrected for multiple comparisons at $p=0.05$ ). This procedure was performed to extract time courses and $\beta$-values for only those clusters reaching the above-mentioned threshold in the statistically more stringent MFX analysis. A cluster extent threshold of 10 voxels was applied to all volume maps.

Analysis of stimulus localizer data (block design). The data from the stimulus localizer experiment were preprocessed and analyzed the same way as the event-related data of the main experiment, using a GLM. Data were first subjected to session-wise FFX analyses for each animal (two scanning days per monkey: M13, 26 runs; M24, 35 runs; M35, 44 runs). The onset of each condition was modeled over the entire $20 \mathrm{~s}$ block extent: (1) red fixation dot only, "stimulus OFF" or "stimulus ON" conditions, (2) bilateral, (3) unilateral left, (4) unilateral right stimulus display. The MFX $t$-map was obtained by contrasting the bilateral (2) "stimulus ON condition" with the fixation-only condition, and thresholded at $p=0.01$ uncorrected (as only 6 con-images entered the MFX analysis). The $t$-score maps were finally projected onto the macaque F99 surface to compare the stimulus representation with maps from the shift and stay contrasts of the main experiment. This was also done in the single subjects for the calculation of overlap between activated voxels obtained by the stimulus localizer and the respective shift and stay contrasts. The single monkey stimulus localizer and stay contrasts (contrasts 1 and 2) for M24 and M35 (scanned with implant coils) were thresholded at FWE corrected for multiple comparisons at $p=0.05$, whereas the less statistically powerful shift map (see Results, contrast 3 ) was thresholded at $p=0.0001$ (uncorrected). In M13 (scanned with external coils), a threshold of $p=0.0001$ (uncorrected) was used for the stimulus localizer and stay-contrasts (1 and 2), and of $p=0.001$ (uncorrected) for the shift contrast (3).
Surface-based projections. For visualization on flat maps or inflated brains, the resulting $t$-maps from the MFX analyses were projected onto the macaque F99 brain (Van Essen, 2004). Flat maps were created using FreeSurfer (http://surfer.nmr.mgh.harvard.edu/). All surface maps where thresholded at a minimal surface area extent of $30 \mathrm{~mm}^{2}$ (http://surfer.nmr.mgh.harvard.edu/fswiki/mri_surfcluster).

Definition of anatomical labels. The anatomical labels, used to designate the positions of our activations on inflated F99-brain surfaces, were derived from three separate sources. Areal labels for V1, V2, V3, V4, V4A, PITd, PITv, and area MT were derived from previous retinotopy experiments. These labels were defined based upon combined retinotopic labels over 5 monkeys (probability maps of $50 \%$ overlap, including M13 and M24) (Janssens et al., 2014).

The outlines of areas $24 \mathrm{~d}, 45,46$, and $5 \mathrm{~V}$ were derived from the Lewis and Van Essen (2000) atlas in F99 space (Lewis and Van Essen, 2000a, b). Area 5V corresponded to area PE. Dorsal and ventral premotor labels F5, F6, and F7, as well as LIP (pooled LIPa and LIPi), FEF, areas 11 and 12, and V6A were based upon Nelissen et al. (2011) and on the template anatomy of M12 (Ekstrom et al., 2009), and were warped to the F99 surface using the FreeSurfer surface-to-surface registration algorithm. Activations not falling into any of those atlases were defined anatomically with the aid of the monkey atlas of Paxinos et al. (2008).

Time courses. The MFX analyses did not allow us to extract raw time courses. To display time courses for ROIs showing a significant attention effect (stay or shift) in the MFX and FFX analyses, all MFX contrasts (1-3) were inclusively masked with the corresponding FFX contrasts (at FWE correction, corrected for multiple comparisons, $p=0.05$ ), applying a cluster extent threshold of 10 voxels. ROI names, atlas source, F99 coordinates centered on the anterior commissure, and respective $t$-values were listed in tables corresponding to each contrast. Next, raw time courses were extracted within a $2 \mathrm{~mm}$ sphere surrounding the closest FFX local maxima (mean \pm SD vector distance of $1.6 \pm 0.7 \mathrm{~mm}$ ), using the FFX group data (207 runs, 69 runs per animal). The raw signal was then high-pass filtered (256 s). An independent baseline was determined for each data point by calculating the moving average of the fMRI signal inside a window of \pm 50 data points with a TR of 2 ( \pm 100 s) (Cui et al., 2009; Arsenault et al., 2013). All conditions were aligned at time point zero, and a peristimulus average percent signal change (PSC) was computed. The baseline (null events) subtracted signal is displayed in all ROI time course plots. All conditions were defined as for the GLM, and the numbers of left and right attention events were equal.

Shift-sensitive ROIs: degree of attentional direction selectivity? To further characterize the activity within each shift-sensitive area, we calculated a two-way repeated-measures ANOVA on the PSC with factors (1) shift versus stay, and (2) left versus right (Yantis et al., 2002) using STATISTICA version 12 (StatSoft 2014; www.statsoft.com).

A shift ROI could show a main effect of shift versus stay (factor 1 ) with or without a directional effect (determined by significance of factor 2, left vs right attention).

A shift-selective ROI, according to our definition, should be transiently activated for bidirectional shifts, without coding the direction of attention (Yantis et al., 2002). In contrast, a shift-sensitive area should 

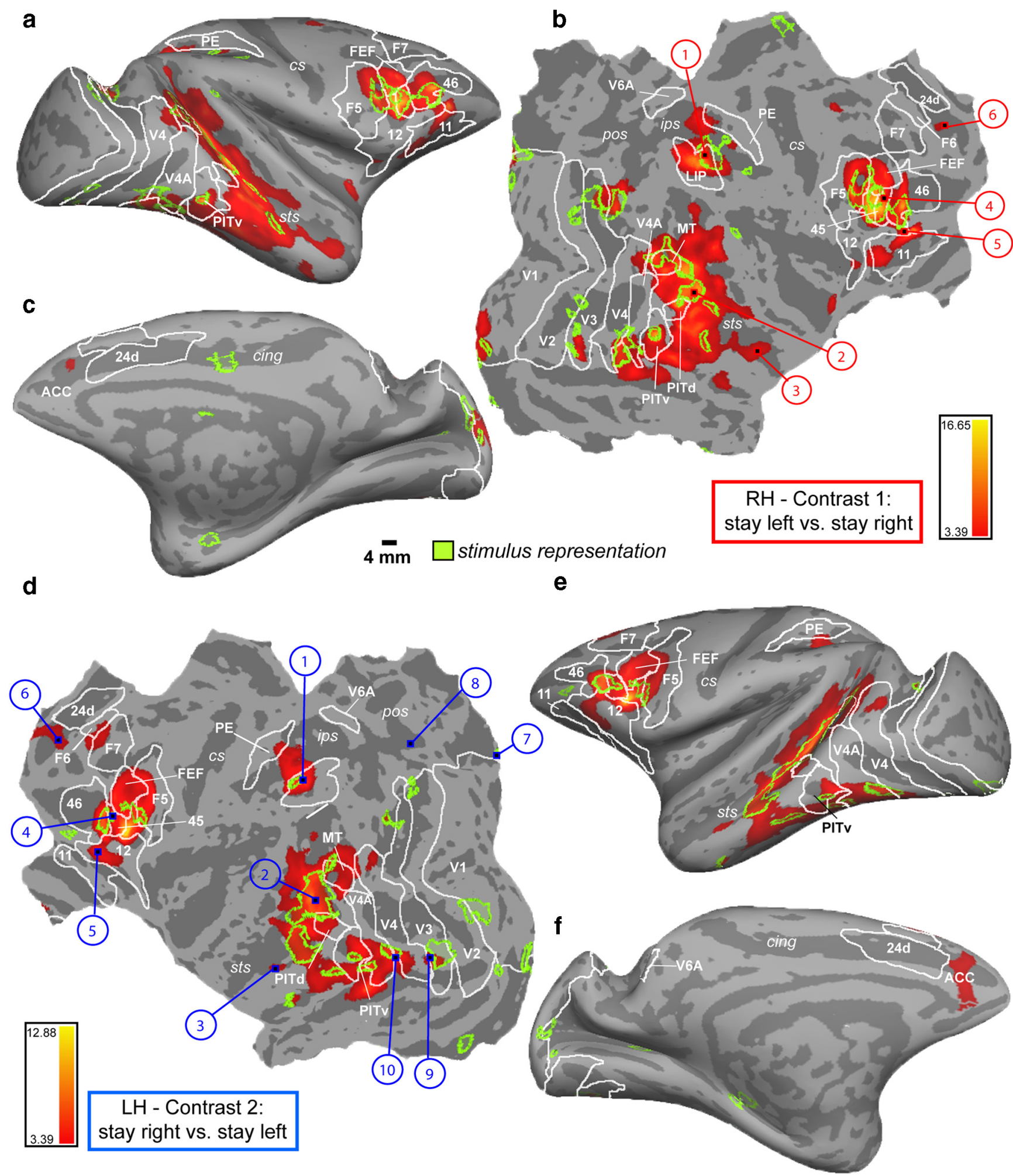

Figure 3. Contralateral modulation of attention. FreeSurfer F99 inflated ( $\boldsymbol{a}, \boldsymbol{e}$, lateral view; $\boldsymbol{c}, \boldsymbol{f}$, medial view) and flattened $(\boldsymbol{b}, \boldsymbol{d})$ surfaces, displaying MFX contrasts 1 and $2(p=0.001, t=3.39)$. $\boldsymbol{a}-\boldsymbol{c}$, Right hemisphere (RH): stay left versus stay right. $\boldsymbol{d}-\boldsymbol{f}$, Left hemisphere (LH): stay right versus stay left. Green transparent overlay, Activation of the stimulus localizer experiment (MFX contrast: bilateral stimulus vs fixation thresholded at $p=0.01, t=2.45$ ). Sulci: sts, Superior temporal; ips, intraparietal; cs, central; pos, parieto-occipital; cing, cingulate. Numbers indicate areas for which example time courses are plotted in Figures 4, 5, 6, and 9. White outlines indicate areal boundaries based on retinotopy labels (probability maps of 5 monkeys, including M13, M24) (Janssens et al., 2014):V1-V4 (A), posterior inferotemporal dorsal (PITd), PITv (ventral), and middle temporal (MT) (Nelissen et al., 2011): F5, F6, and F7, as well as LIP, FEFs, V6A (Lewis and Van Essen, 2000b): 24 d, 45, 46, 5 V (PE).

show a main effect of shifting attention, and a main directional effect. Finally, within each ANOVA, we also performed post hoc tests (Fisher's least significant difference) to test for directional selectivity of the shift conditions only (shift left vs shift right).
Analysis of behavioral data. The behavioral data of each monkey were analyzed from all runs that were included in the group analysis. As for the GLM, behavioral data were obtained from at least 3 consecutively correctly executed trials. 
Table 4. Local maxima of contrast 1 (stay-left vs stay-right) ${ }^{a}$

\begin{tabular}{|c|c|c|c|c|c|}
\hline \multicolumn{6}{|c|}{ F99 space, $x, y, z$ (mm) } \\
\hline Area & Hemisphere & Atlas & (MFX) & Voxel, $t$-value & ROI (Figs. 4-6, 9 \\
\hline V1 & Right & $\mathrm{R}$ & $9,-50,5$ & 6.03 & \\
\hline V1/2v & Right & $\mathrm{R}$ & $11,-47,-8$ & 4.14 & \\
\hline V2/3v & Right & $\mathrm{R}$ & $-9,-40,-2$ & 6.70 & \\
\hline pdV2 & Left & $A$ & $-7,-40,6$ & 6.32 & \\
\hline V3v & Right & $\mathrm{R}$ & $16,-39,-6$ & 6.84 & \\
\hline Cerebellum & Left & $A$ & $-15,-38,-13$ & 6.11 & \\
\hline V3d & Right & $\mathrm{R}$ & $18,-34,10$ & 10.68 & \\
\hline V4/V4Av & Right & $\mathrm{R}$ & $25,-32,-8$ & 10.08 & \\
\hline V4d & Right & $\mathrm{R}$ & $25,-27,10$ & 9.06 & \\
\hline LIP & Right & $\mathrm{N}$ & $12,-26,16$ & 12.40 & 1 \\
\hline FST & Right & $\mathrm{L}$ & $22,-24,-2$ & 12.88 & 2 \\
\hline V4Ad & Right & $\mathrm{R}$ & $-27,-24,3$ & 8.77 & \\
\hline FST & Right & $A$ & $19,-23,2$ & 11.08 & \\
\hline $\mathrm{dLGN}$ & Right & $A$ & $16,-22,-2$ & 6.47 & Subcortical \\
\hline SC & Right & $A$ & $3,-20,0$ & 7.19 & Subcortical \\
\hline PITd & Right & $\mathrm{R}$ & $28,-19,-2$ & 12.88 & \\
\hline TE & Right & $A$ & $28,-18,-10$ & 9.18 & \\
\hline v caud & Right & $A$ & $16,-7,-9$ & 7.51 & Subcortical \\
\hline TEa & Right & $A$ & $21,-4,-12$ & 6.03 & 3 \\
\hline $\mathrm{d}$ caud & Right & $A$ & $5,-2,8$ & 8.40 & Subcortical \\
\hline Area 45 & Right & $L$ & $21,4,11$ & 11.06 & 4 \\
\hline FEF & Right & $\mathrm{N}$ & $14,5,15$ & 8.71 & \\
\hline Area 45 & Right & $\mathrm{N}$ & $18,9,9$ & 11.51 & \\
\hline Area 46p & Right & $\mathrm{L}$ & $18,10,13$ & 12.14 & \\
\hline $\mathrm{ACC}$ & Right & A & $5,14,16$ & 4.23 & 6 \\
\hline Area 12 & Right & $\mathrm{N}$ & $18,17,11$ & 10.13 & 5 \\
\hline
\end{tabular}

$\overline{{ }^{a} \text { ROIs obtained from the MFX analysis at } p=0.001 \text { (cluster extent threshold of } 10 \text { voxels), displaying activations that }}$ are also present in the same FFX contrast at FWE correction (corrected for multiple comparisons at $p=0.05$ ), listed from posterior to anterior for contrast 1. Columns indicate the following: (1) ROI name; (2) hemisphere; (3) atlas used to determine anatomical positions (R, Retinotopy labels from Janssens et al., 2014; L, labels from Lewis and Van Essen, 2000a, b; N, labels from Nelissen et al., 2011; A, anatomical sections, Paxinos et al., 2008); (4) coordinates corresponding to the RM112 brain in F99 space (centered on the anterior commissure); and (5) $t$-values of the local maxima for the given contrast. Last column, Example ROls as selected for plotting in Figures $4-6$ and 9. LGN, Lateral geniculate nucleus; $\mathrm{SC}$, superior colliculus; v/d caud, ventral/dorsal caudate; pdV2, peripheral dorsal V2.

Probing the allocation of attention: dimming of the relevant stimulus. Percentage hits (detected relevant dimmings) and misses (undetected relevant dimmings) were calculated with respect to the overall number of response trials (relevant dimmings). False alarms (responses to irrelevant dimmings) were calculated relative to the total number of irrelevant dimmings.

Reaction times were analyzed to assess whether (1) monkeys reacted equally quickly after dimmings of relevant stimuli in the left or right visual hemifield and whether (2) differences in reaction times existed between the dimmings occurring in the three trial types (null, stay, and shift). Reaction times were sampled for all correctly performed response trials during which a dimming of the relevant stimulus occurred no more than $600 \mathrm{~ms}$ after trial onset.

Across-session repeated-measures ANOVAs were performed for each animal (M13, 9; M24, 12; M35, 10), with factors condition (null, stay, shift) and direction of attention (left, right), for reaction times, hits, and misses (Tables 1, 2).

Eye-movement data during fixation-only trials. Eye-position data were analyzed for the fixation trials (correct sequences of at least 3 consecutive trials, excluding dimmings or rewards) that were included in the GLM. This analysis was intended to track the eye position for correctly performed stimulus sequences, within a fixation window of $2 \times 3$ degrees, with respect to each condition (Fig. 2). The most informative first $600 \mathrm{~ms}$ after trial onset were included in the analysis and sorted condition-wise (as for the GLM). For shift events, the second half of the sampled data was used, reflecting the endpoint of the shift (301-600 ms). This was done because, at time point zero, attention was still deployed to the opposite hemifield. Trials with blinks were excluded from the eye-movement analysis (M13, 8.11\%; M24, 19.4\%; M35, 22.5\%). Eye movement deviations in degrees of visual angle (from the midline) for each animal were entered into a session-wise 3 (condition: null/stay/shift) $\times 2$ (direction of attention: left/right) repeated-measures ANOVA (Table 3 ).
Table 5. Local maxima of contrast 2 (stay-right vs stay-left) ${ }^{a}$

\begin{tabular}{|c|c|c|c|c|c|}
\hline \multirow[b]{2}{*}{ Area } & \multirow[b]{2}{*}{ Hemisphere } & \multirow[b]{2}{*}{ Atlas } & \multicolumn{2}{|l|}{ F99 space, $x, y, z(\mathrm{~mm})$} & \multirow[b]{2}{*}{ ROl (Figs. 4-6,9) } \\
\hline & & & (MFX) & Voxel, $t$-value & \\
\hline V1 & Left & $\mathrm{R}$ & $-6,-48,6$ & 3.88 & 7 \\
\hline pdV2 & Right & A & $7,-40,7$ & 5.95 & 8 \\
\hline V3v & Left & $\mathrm{R}$ & $-15,-39,-7$ & 5.79 & 9 \\
\hline $\mathrm{V} 2 / 3$ & Left & $\mathrm{R}$ & $-8,-38,13$ & 4.15 & \\
\hline V4v & Left & $\mathrm{N}$ & $-23,-31,-8$ & 8.77 & 10 \\
\hline LIP & Left & $\mathrm{N}$ & $-10,-26,16$ & 12.95 & 1 \\
\hline V4A/PITV & Left & $\mathrm{R}$ & $-23,-25,-9$ & 9.67 & \\
\hline MSTd & Left & A & $-17,-24,6$ & 8.90 & \\
\hline FST & Left & L & $-22,-23,-3$ & 12.08 & 2 \\
\hline dLGN & Left & A & $-12,-22,1$ & 5.34 & Subcortical \\
\hline PITd & Left & $\mathrm{R}$ & $-22,-20,-5$ & 10.79 & \\
\hline SC & Left & A & $-3,-20,-1$ & 4.26 & Subcortical \\
\hline v caud & Left & A & $-14,-6,-10$ & 9.02 & Subcortical \\
\hline $\mathrm{d}$ caud & Left & A & $-5,-6,8$ & 6.87 & Subcortical \\
\hline TEa & Left & A & $-22,-4,-12$ & 8.63 & 3 \\
\hline F5 & Left & $\mathrm{N}$ & $-14,-1,15$ & 7.80 & \\
\hline Area 45 & Left & L & $-20,4,13$ & 9.35 & 4 \\
\hline $\mathrm{FEF} / 45$ & Left & L & $-18,9,8$ & 16.65 & \\
\hline Area 46p & Left & L & $-18,8,14$ & 13.44 & \\
\hline SEF/F7 & Left & $\mathrm{R}$ & $-4,12,21$ & 5.49 & \\
\hline Area 12 & Left & $\mathrm{N}$ & $-17,15,10$ & 6.68 & 5 \\
\hline $\mathrm{ACC}$ & Left & A & $-3,15,15$ & 6.26 & 6 \\
\hline
\end{tabular}

${ }^{a}$ ROIs obtained from the MFX analysis at $p=0.001$ (cluster extent threshold of 10 voxels), displaying activations that are also present in the same FFX contrast at FWE correction $(p=0.05)$. Same conventions as in Table 4 , but for contrast 2. SEF, supplementary eye field. Columns indicate the following: (1) ROI name; (2) hemisphere; (3) atlas used to determine anatomical positions (R, Retinotopy labels from Janssens et al., 2014; L, labels from Lewis and Van Essen, 2000a, b; N, labels from Nelissen et al., 2011; A, anatomical sections, Paxinos et al., 2008); (4) coordinates corresponding to the RM112 brain in F99 space (centered on the anterior commissure); and (5) $t$-values of the local maxima for the contrast stay left versus right. Last column, Example ROIs as selected for plotting in Figures $4-6$ and 9. LGN, Lateral geniculate nucleus; SC, superior colliculus; v caud, ventral caudate; pdV2, peripheral dorsal V2.

\section{Results}

\section{Behavior}

The animals were extensively trained ( $>4$ months) to covertly attend to the relevant shapes (square and circle for M13/M35, triangle and diamond for M24) during all event types (null, stay, and shift events). Subjects almost never responded to dimmings of irrelevant shapes, with a false-alarm rate not significantly different from zero (Table 1).

Longer reaction times and an increased number of missed dimmings after shift trials compared with stay trials have been reported in humans (Molenberghs et al., 2007). Probably because of the extensive training regimen of our monkeys' prior scanning, they showed no significant differences in reaction times (RT), hits $(\mathrm{H})$, and misses $(\mathrm{M})$, indicating that they performed equally well across event types (repeated-measures ANOVA with conditions null, stay, and shift; Table 2).

Hits and false alarm rates in Table 2 provide a direct behavioral measure of the animal's focus of attention. However, because relevant/irrelevant dimmings occurred only rarely $(2 \times 14 \%$ of the trials), we also analyzed small deviations in eye position across conditions. These provide an alternative, yet continuous, behavioral measure of the monkey's allocation of attention (Engbert and Kliegl, 2003; Laubrock et al., 2005; Xiao et al., 2007), requiring no explicit operant response. By plotting minor changes in eye positions immediately after a change in trial type (stay, shift, or null) in Figure 2, small deviations in eye position toward the relevant stimuli could be detected, indicating the side to which the monkey's attention was directed. This was significant for M13, M24, but not for M35 (Table 3; rANOVA condition (3) $\times$ direction of attention (2); direction of attention (left vs right): $\mathrm{M} 13, F_{(1,8)}=$ $6.67 ; p=0.03 ; \mathrm{M} 24, F_{(1,11)}=24.67 ; p=0.0004 ; \mathrm{M} 35, F_{(1,9)}=$ $0.09 ; p=0.78$ ). The overall trend in eye position shifts (Fig. 2) 

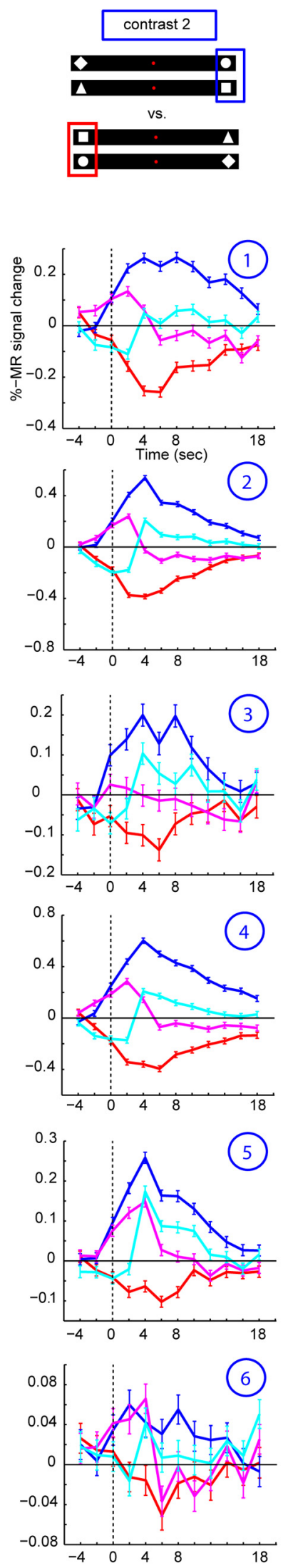
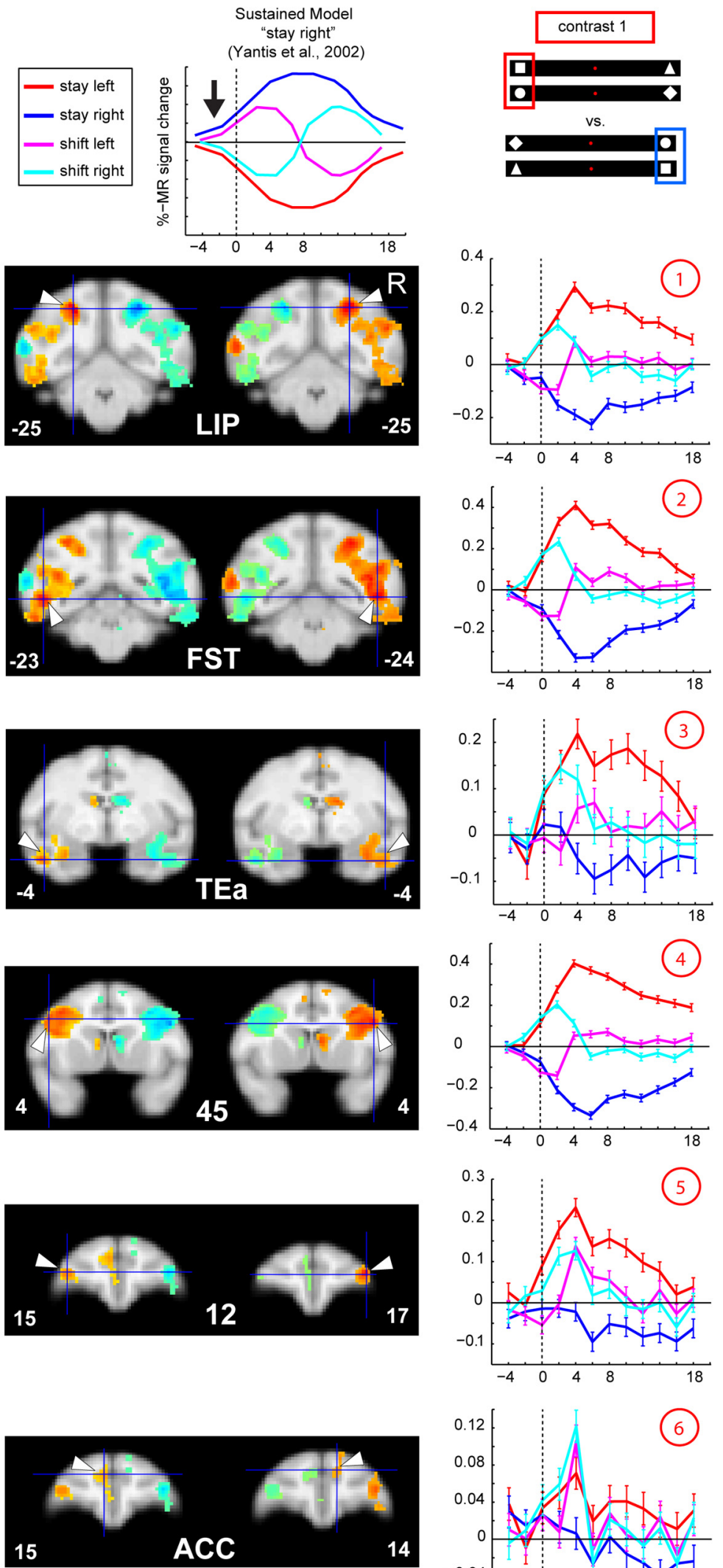

Figure 4. Contralateral modulation of attention, cortical areas. Group MFX data in 112-RMatlas (McLaren etal., 2009) aligned to the F99 group space (anterior/posterior levels in coronal slices indicated with respect to the anterior commissure), thresholded at $p=0.001$ (uncorrected), cluster extent threshold of 10 voxels. Middle left panels (contrast 2), Hot colors represent activations for stay right versus stay left. Cold colors represent deactivationsfor stayrightversus stay left. Middlerightpanels (contrast1), Hotcolors representactivationsfor stayl leftversusstay right. Cold colors represent deactivations for stay leftversus stay right. PSC plotted from rawtime courses against the baseline (null events), of the ROls indicated with the white arrows. The polanity of all signal changevalues has been inverted, as increase in signal produces decrease in the MION CBV maps (see Materials and Methods). Numbers indicate the ROl locations on the flatmap in Figure 3. Middle/top, For illustrative purposes, we depict the "sustained model" (example for "right attention") (adapted from Yantis etal., 2002). 

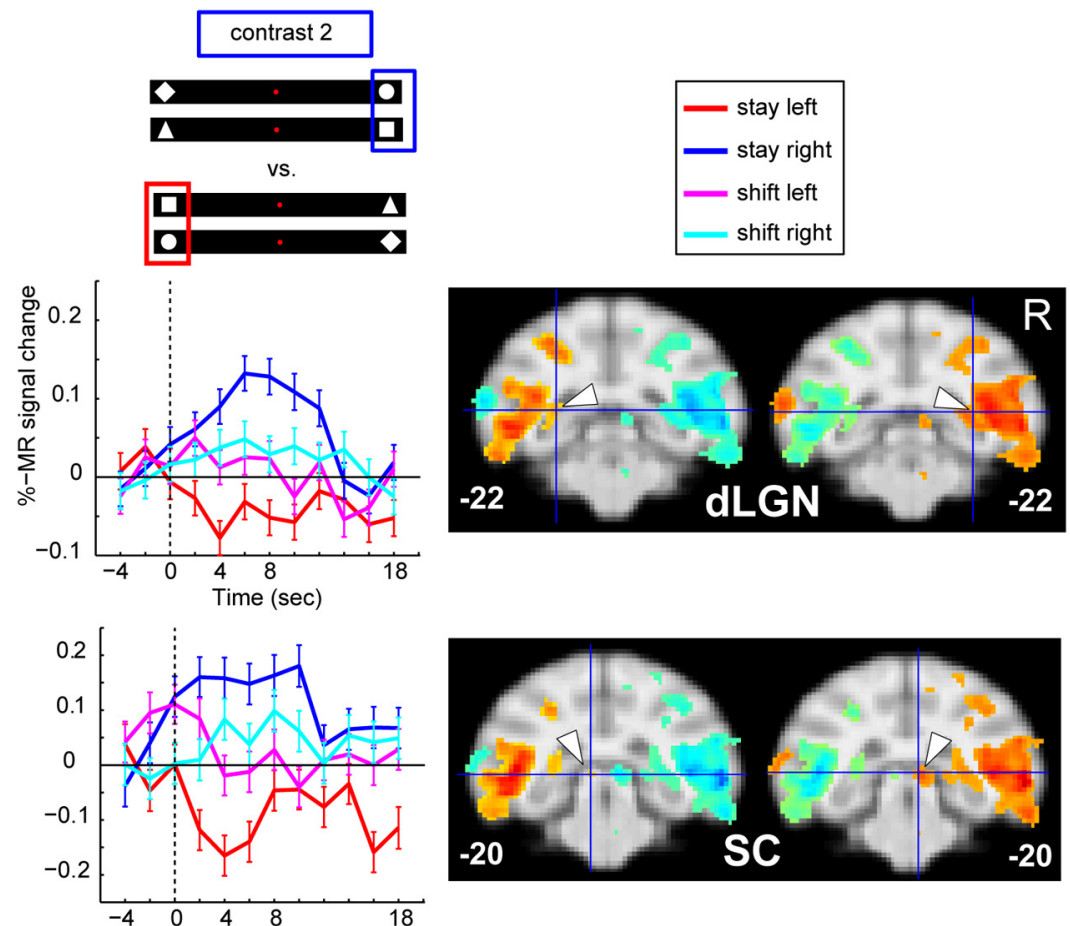

$-20$
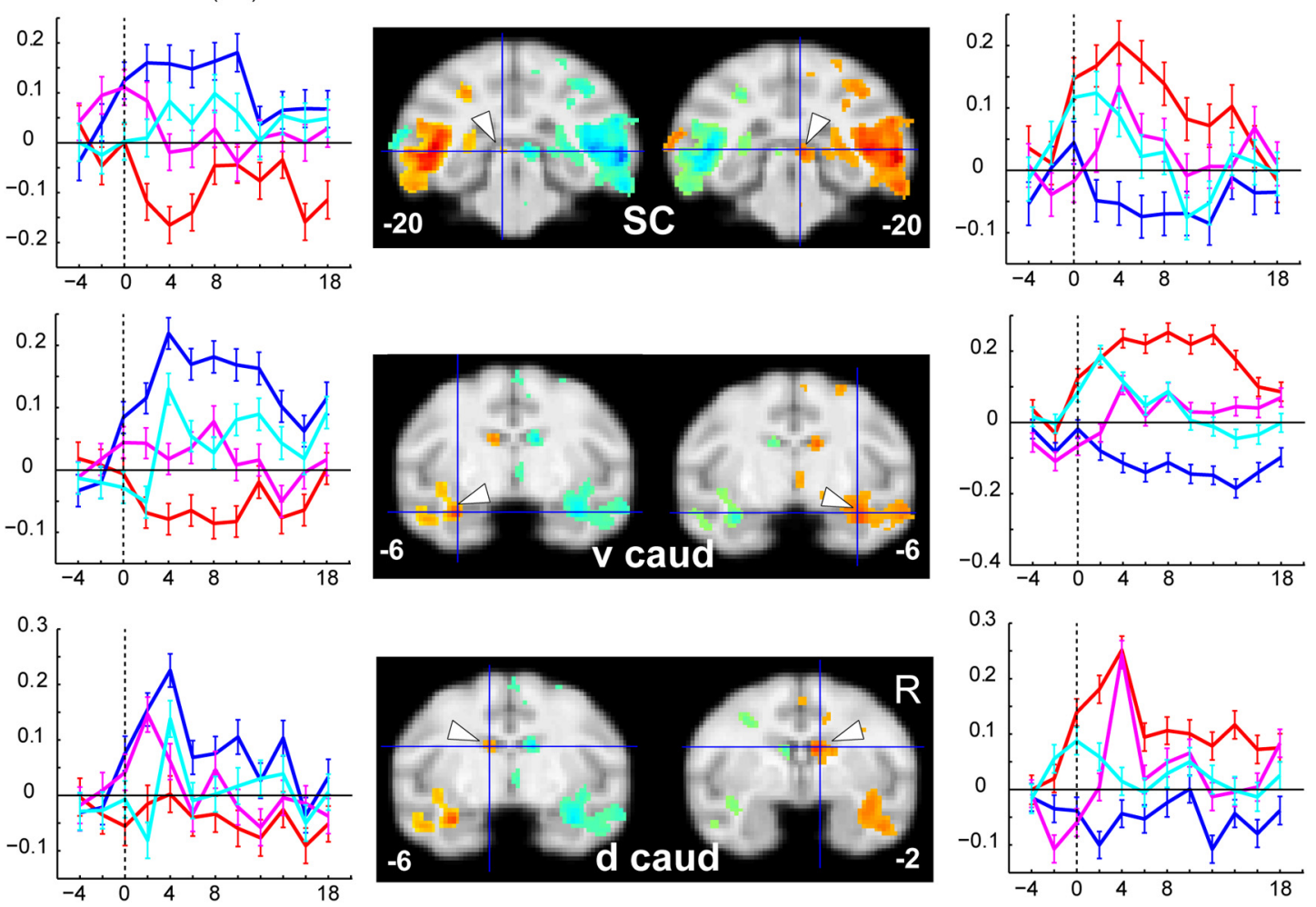

Figure 5. Contralateral modulation of attention, subcortical areas. Same conventions as in Figure 4. dLGN, Dorsal lateral geniculate nucleus; SC, superior colliculus; v caud, ventral caudate nucleus; d caud, dorsal caudate nucleus.

provides additional evidence that monkeys effectively attended to the relevant stimuli.

M13 fixated without interruption for an average of $4 \pm 1.4$ consecutive trials (mean $\pm \mathrm{SD}$ ), whereas M24 averaged $15 \pm 13.6$ consecutive trials, and M35 $14 \pm 15.3$. Only trial sequences during which monkeys fixated for at least 3 consecutive trials without dimming events and rewards were included in the statistical GLM analyses.

The average fixation performance of analyzed runs (within a fixation window of $2 \times 3$ degrees) for M13 ranged from $85 \%$ to $95 \%$ across runs, $93 \%$ to $100 \%$ for M24, and $85 \%$ to $99 \%$ for M35.

\section{Contralateral attention signals}

We first identified brain regions showing fMRI activity modulated by contralateral attention using the contrast stay-left versus stay-right (contrast 1, Fig. 3a-c, right hemisphere), and vice versa (contrast 2, Fig. $3 d-f$, left hemisphere). Modulation of fMRI ac- tivity during contralateral stay was observed, for example, in visual cortex (V1, V2, V3, V4, V4A, MT, FST PITv/d, area TE, posterior superior temporal sulcus [STS]) with a clear tendency for more widespread and stronger attention-dependent modulations in higher-order areas (Kastner and Ungerleider, 2000). Also parietal (LIP spreading into PE) and frontal areas 45, FEF, 46, 11, 12 , F5, ACC, and SEF/F7 showed modulation of activity by contralateral attention. This was also the case for subcortical regions in both hemispheres, such as the dorsal caudate nucleus, the ventral caudate, the dorsal lateral geniculate nucleus, and the superior colliculus (Tables 4, 5).

Time course of contralateral attention signals

A time course analysis was used to illustrate the properties of ROIs showing significant differences between stay right and stay left. Their raw time courses, plotted against a null trial baseline (see Materials and Methods), showed a pattern similar to the 
sustained attention signal previously described and modeled by Yantis et al. (2002) (Fig. 4, top, example for a stayright selective ROI). In addition to producing the strongest activation for the contralateral stay condition and deactivation for the ipsilateral irrelevant shapes in these stay ROIs, attention shifts to the ipsilateral visual hemifield (Fig. 4, left column, magenta plots, example for shiftleft) resulted in a peak in fMRI activity $\sim 2-4 \mathrm{~s}$ after the shift, followed by a deactivation $\sim 6-10 \mathrm{~s}$. These time periods correspond, respectively, to the initiation of the shift in the contralateral hemifield and the reengagement of attention ipsilaterally relative to the ROI. The opposite activation pattern was observed for a shift to the right (shift-right, Fig. 4, left column, cyan lines). As already shown in humans (Yantis et al., 2002), these stay ROIs revealed modulation of contralateral attention originating before time point zero, indicated by Figure 4 (top, black arrow, Sustained Model). This activation pattern was not unexpected because attention had already been deployed, for at least one trial, to the same target location, even before the exchange of the two relevant shapes.

Posterior parietal areas, such as LIP, areas in inferotemporal cortex, the STS (for example, area FST, shown in Fig. 4), and lateral prefrontal areas, such as areas 12 and 45, displayed the prototypical time course indicative of strong contralateral attentional signals illustrated in Figure 4, with the exception of ACC (Fig. 4, bottom).

Subcortical areas, such as the dorsal lateral geniculate nucleus, the superior colliculus, as well as ventral caudate and the dorsal caudate nucleus, also exhibited profound modulation of activity for contralateral attention, in accordance with the sustained model (Fig. 5). Visual areas V3 and V4 also showed this sort of contralateral attentional modulation, as did V1 to a lesser extent (Fig. 6). Counterintuitively, caudal occipital regions along the medial wall, close to peripheral dorsal V2 (Fig. 6, \#8), showed the opposite activation pattern, indicating deactivations with respect to the contralateral attended stimulus, as described previously (Kagan et al., 2010).

\section{Shift-sensitive activations}

By contrasting shift with stay events, we could identify shift-sensitive activations

(Fig. 7, hot colors). Table 6 lists the location and $t$ values of the ROIs activated by shifts, as obtained from the MFX analysis across sessions (and also present in the FFX analysis). Posterior shift-sensitive activations were located in caudo-dorsal occipital contrast 2

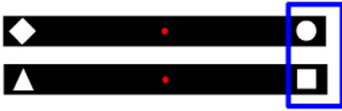

VS.
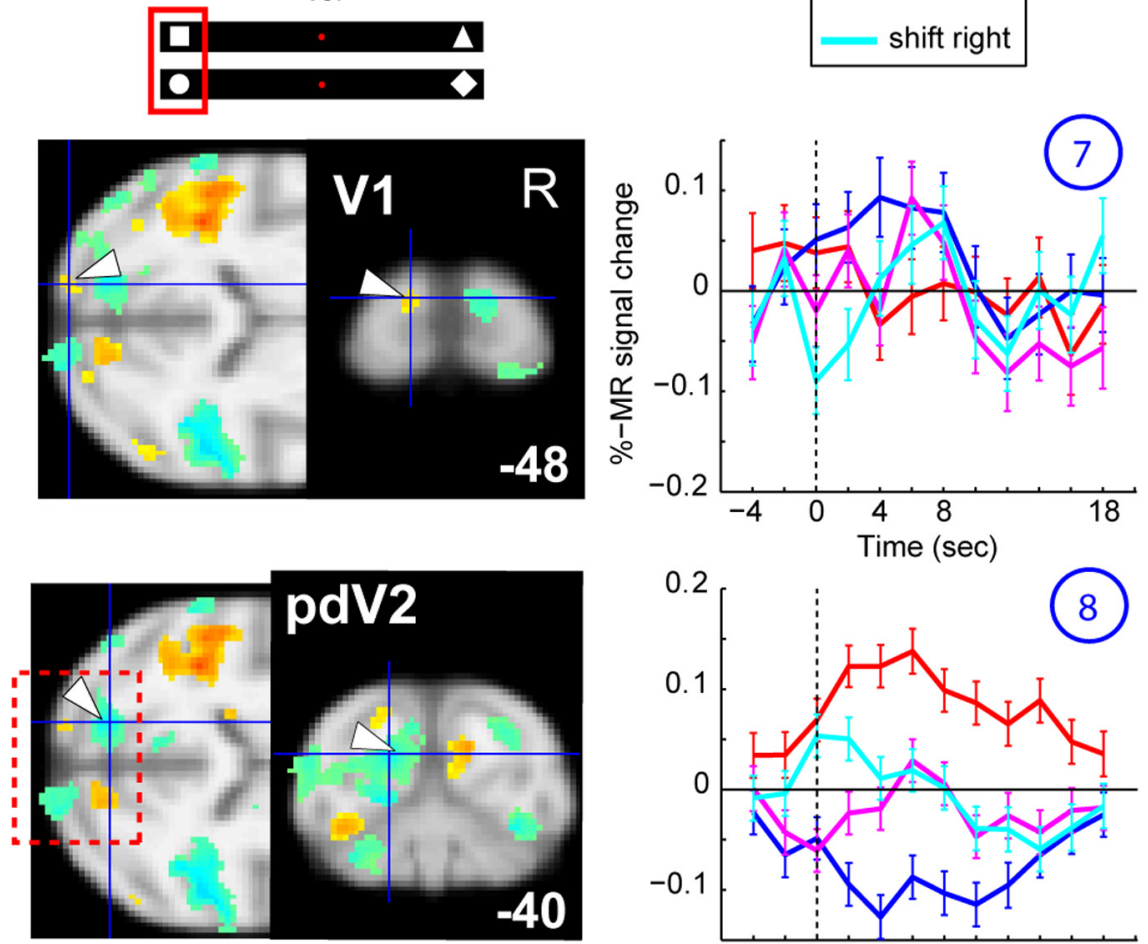

0.2
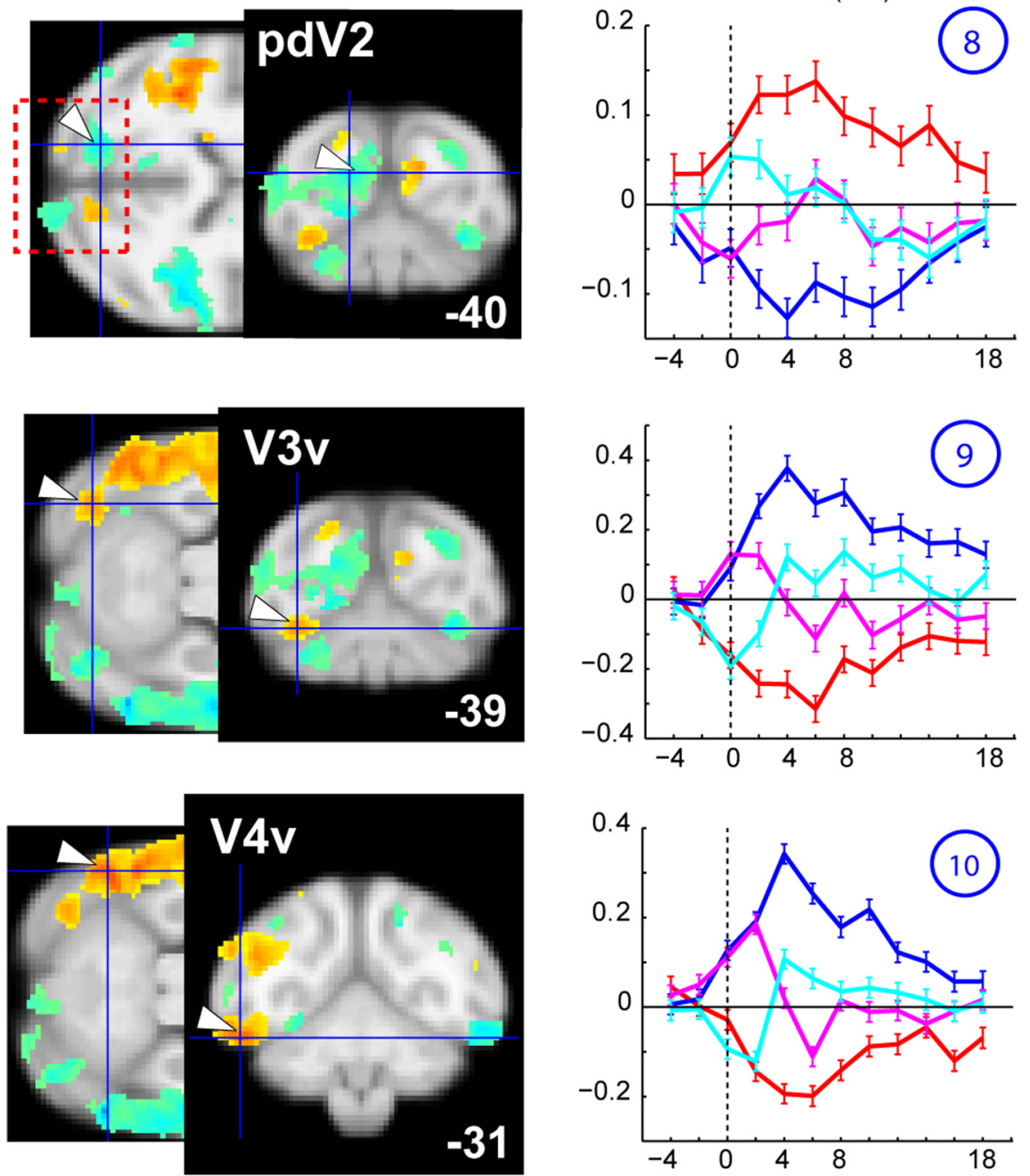

Figure 6. Contralateralmodulation ofattention, visualareasV1-V4. Rawtimecourses forleftV1-V4forcontraststayrightversusstayleft. Same conventions as in Figure 4 for contrast2. Left panels, Horizontal sections (posterior to the STS), as well as coronal sections. pdV2, Peripheral dorsal V2.

cortex, the most posterior portion of the STS (termed TPOC), posterior medial parietal areas V6, V6A, medial intraparietal area (MIP), and left somatomotor cortex. Frontal activations for shifting were situated in areas F6, 11, 12, anterior portions of area 46, 

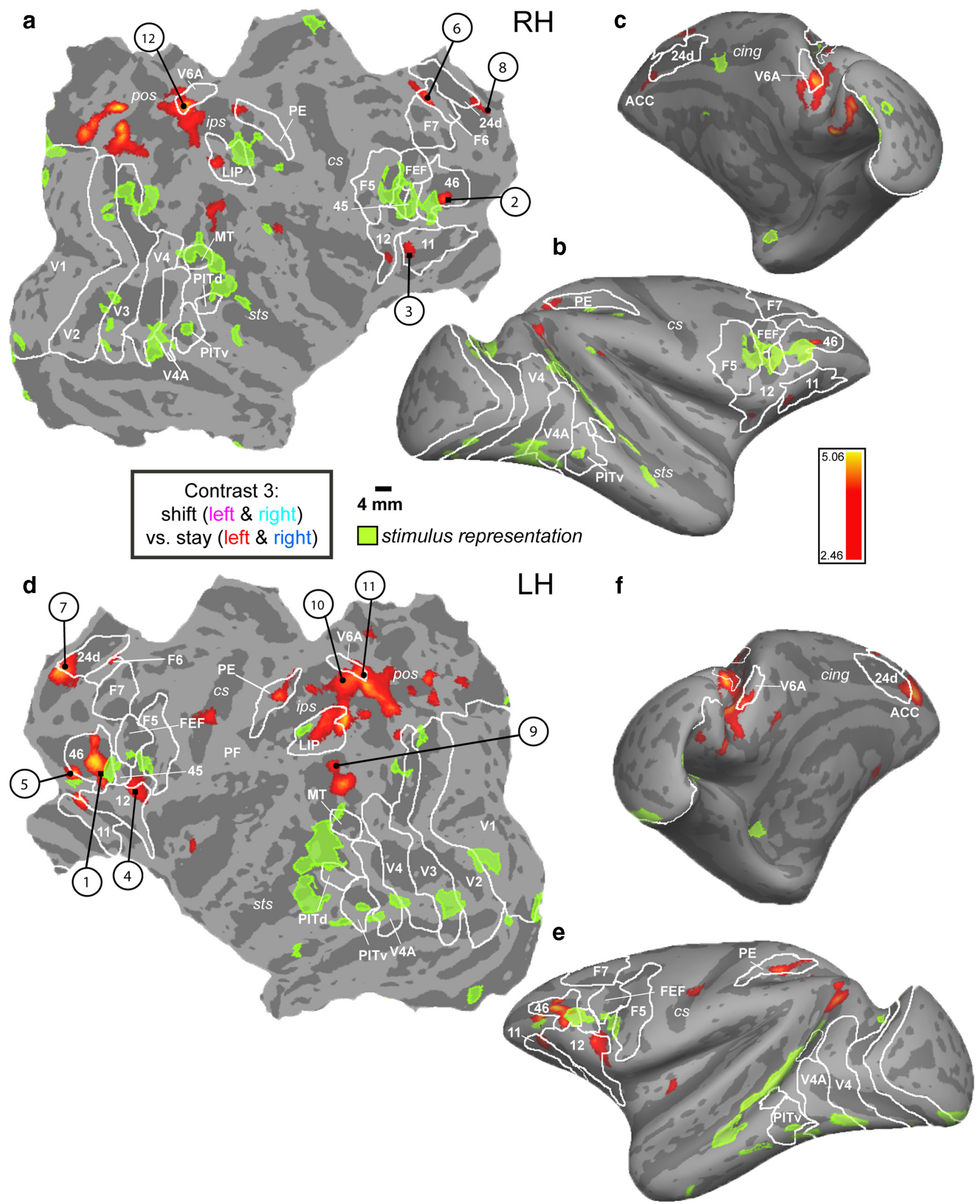

Figure 7. Shift-related activation does not overlap with stimulus representation. FreeSurfer F99 inflated $(\boldsymbol{c}, \boldsymbol{b}, \boldsymbol{f}, \boldsymbol{e})$ and flattened $(\boldsymbol{a}, \boldsymbol{d})$ surfaces. MFX analysis, contrast 3 (shift left and right vs stay left and stay right) at $p=0.01$. Green transparent overlay, Activation of the stimulus localizer (MFX: contrast, bilateral stimulus vs fixation, same conventions/contrast as in Fig. 3). Numbers indicate areas of which example time courses are plotted in Figures 9,11 , and 12. Sulci and areal boundaries: same conventions as in Figure 3 . 
Table 6. Local maxima of contrast 3 (shift vs stay) $^{a}$

\begin{tabular}{|c|c|c|c|c|c|c|c|c|}
\hline \multirow[b]{2}{*}{ Area } & \multirow[b]{2}{*}{ Hemisphere } & \multirow[b]{2}{*}{ Atlas } & \multirow[b]{2}{*}{ F99 space, x, y, z (mm) (MFX) } & \multirow[b]{2}{*}{ Voxel, $t$-value } & \multicolumn{3}{|l|}{$2 \times 2$ ANOVA } & \multirow[b]{2}{*}{ ROI (Figs. 7, 9} \\
\hline & & & & & Shift versus stay: $F_{(1,206)}$ & Left versus right: $F_{(1,206)}$ & Interaction: $F_{(1,206)}$ & \\
\hline $\mathrm{cmoc}$ & Left & $\mathrm{R}$ & $-2,-38,9$ & 3.99 & $7.72^{*}$ & $4.96^{*}$ & 0.00 & \\
\hline V6A & Left & $\mathrm{N}$ & $-5,-35,12$ & 4.35 & $10.92^{*}$ & 1.29 & 0.12 & 11 \\
\hline V6A & Right & $\mathrm{N}$ & $7,-36,12$ & 4.27 & $8.40^{*}$ & 0.31 & 0.47 & 12 \\
\hline V6 & Right & $\mathrm{N}$ & $5,-37,7$ & 3.10 & $8.51^{*}$ & 0.14 & 0.52 & \\
\hline MIP & Left & A & $-6,-31,14$ & 4.49 & $7.28^{*}$ & 0.60 & 0.32 & 10 \\
\hline F6 & Right & $\mathrm{N}$ & $2,5,21$ & 4.16 & $7.27^{*}$ & 0.02 & 0.24 & 6 \\
\hline Area 12 & Left & $\mathrm{N}$ & $-22,7,3$ & 3.11 & $17.71^{* *}$ & $19.94^{* *}$ & 0.18 & 4 \\
\hline Area 11/12 & Right & $\mathrm{N}$ & $20,11,6$ & 3.54 & $16.56^{* *}$ & $68.84^{* *}$ & $26.39 * *$ & 3 \\
\hline Area 46 & Left & $\mathrm{L}$ & $-17,12,13$ & 4.01 & $9.65^{*}$ & $30.13^{* *}$ & 2.32 & 1 \\
\hline Area 46 & Right & L & $15,11,11$ & 4.37 & $5.80^{*}$ & $6.18^{*}$ & $6.08^{*}$ & 2 \\
\hline $\mathrm{ACC}$ & Left & $A$ & $-4,13,13$ & 4.91 & $15.02^{* *}$ & 0.61 & 0.00 & 7 \\
\hline
\end{tabular}

${ }^{a}$ Clusters are shown that are significant for contrast 3 in both the MFX analysis ( $p=0.01$; Fig. 7 ) and the FFX analysis (FWE corrected for multiple comparisons at $p=0.05$ with a minimum cluster extent threshold of 10 voxels. Column 5 displays the $t$-values for the contrast shift versus stay. Same conventions as in Tables 4 and 5 for table columns $1-5$ and 9 . Columns $6-8$ show results of the two-way repeated measures ANOVA, with factors (1) shift versus stay and (2) left versus right attention, and their interaction, computed with PSCs obtained from the $\beta$-values for each ROI separately. All ROls are plotted and sorted in Figure 10 according to their main effects. Areas marked with "**" for factor "left versus right" attention also show a direction-selective shift signal (post hoc test with Fisher's LSD of shift left vs shift right; Figure 10, blue stars). Example raw time courses for ROIs listed in the last column are plotted in Figure 11 and 12 . ROIs with a main effect of shifting and main effect left versus right attention are indicated in Figure 13 (orange), and those without direction effect are indicated in yellow. cmoc, Caudo-medial-occipital cortex.

${ }^{*} p<0.5 ;{ }^{* *} p<0.001$.

part of the ACC, and the lateral bank of the anterior principal sulcus (aPCS). Comparing the maximal $t$ values for contralateral attention (contrast $1, t_{\max }=12.88$; contrast $2, t_{\max }=16.65$ ) with those for shifts (contrast 3, $t_{\max }=5.06$ ), listed in Tables 4, 5, 6, revealed major differences in statistical power for contralateral stay and shifts. We therefore applied a more liberal threshold for localizing shift-sensitive regions. It has to be noted that computing a conjunction between the contrasts shift left versus stay (left and right) and shift right versus stay, as obtained from the MFX analysis, resulted in virtually the same activated areas as for main contrast 3 (Fig. 8, coronal slices).

Overlap of stimulus representation with shift and stay signals First, we compared the direction-sensitive stay activations with the actual sensory representation of the stimulus as measured during the independent localizer experiment (Fig. 3, green outlines overlaying the contralateral stay activity). In most cortical sites, modulation of fMRI signals by contralateral attention was enhanced in areas where the stimuli are represented. Overall, activations overlapped in striate and extrastriate visual cortex, such as V1, V3, V4, and V4A, the MT cluster, PITv/d, but also in areas more anteriorly in the STS. Overlap was also observed in the lateral bank of the IPS (LIP) and (pre)frontal areas, including anterior F5, FEF, area 45, and posterior area 46. In single animals, $46 \%$ of the voxels (M13, 43\%; M24, 52\%; M35, 43\%) activated during the stimulus localizer experiment showed a contralateral attention signal (both contrasts thresholded at $p=0.0001$, uncorrected, for M13; and at FWE corrected for multiple comparisons at $p=0.05$, for M24/M35, given the implant coils; see Materials and Methods). The latter numbers are threshold dependent. Therefore, we also showed virtually unthresholded activations of the stimulus localizer experiment ( 6 sessions entering the MFX analysis; Fig. 9, hot colors). This analysis confirmed that the majority of contralateral stay activity (white outlines, 31 sessions entering the MFX analysis, same as in Fig. 3, hot color) is indeed restricted to areas were the stimuli are represented. Next, we plotted the PSCs obtained during the stimulus localizer experiment within the stay-selective ROIs (Fig. 9, red and blue panels).
This quantitative analysis also showed that most voxels showing a contralateral stay signal are indeed driven by passive viewing of the same contralateral stimulus during the localizer experiment. The only exceptions were rostral ACC, and area F7 (SEF) in frontal cortex, which showed a pronounced and sustained contralateral attention effect, although they were not activated during the stimulus localizer experiment (Figs. 3, 9, \#6 and \#11, blue/red panels), as well as dorsal caudate nucleus (Fig. 9, dCaud) bilaterally.

Second, unlike most regions selectively modulated by contralateral sustained attention, the shift-sensitive activations were distinct from the stimulus representations, except for area 46 (hot colors in Fig. 7 correspond to yellow outlines and black panel in Fig. 9). In single animals, the percentage of voxels activated during the stimulus localizer test that coincided with activations driven by attention shifts (M13, $p=0.001$, uncorrected; and M24/M35, $p=0.0001$, uncorrected, given the implant coils; see Materials and Methods) was very small (M13, 2\%; M24, 6\%; M35, 3\%), whereas the stimulus localizer was thresholded even higher than the shift contrast ( $p=0.0001$, uncorrected, for M13; and at FWE corrected for multiple comparisons at $p=0.05$, for M24/M35). Thus, the majority of shift-sensitive areas are not activated during the stimulus localizer test. This strongly suggests that attentional shift signals represent a distinct attention process compared with stay signals, executed by a separated neural substrate.

\section{Do all shift-sensitive regions compute direction-independent shift signals?}

Using the same contrast (shift vs stay) as the human study, where the major shift activation was confined to SPL (Molenberghs et al., 2007), we observed several shift-sensitive activations outside caudo-medial parietal (and occipital) cortex in the monkey. It has to be noted that this contrast does not differentiate between direction-dependent and -independent attention signals. First, to distinguish between these two, we computed a two-way repeatedmeasures ANOVA with factors condition (shift, stay) and direction of attention (left, right), exactly as in Yantis et al. (2002). We 


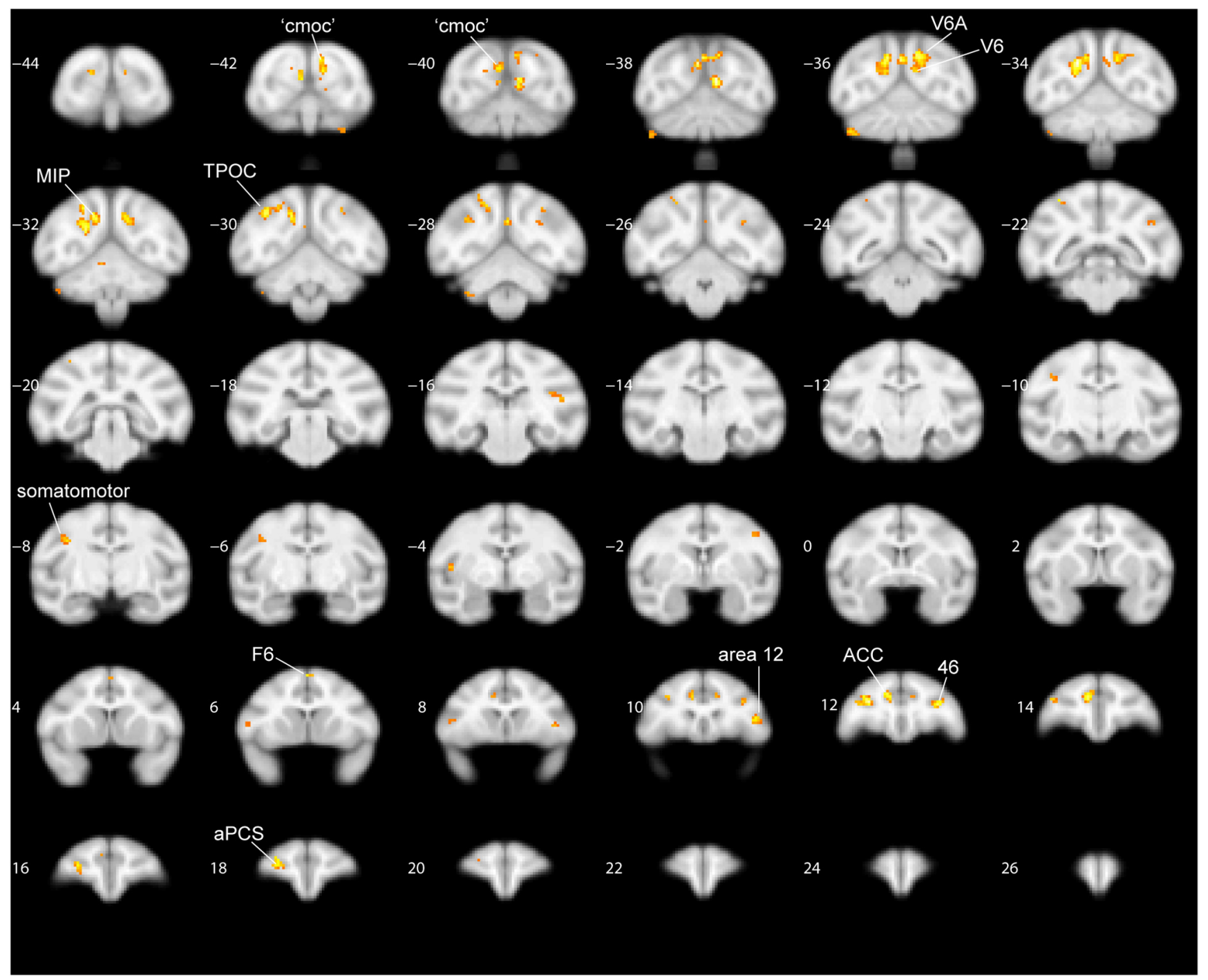

Figure 8. Shift-related activations displayed on coronal slices. Conjunction of contrasts [shift left vs stay left/right] ^ [shift right vs stay left/right] are shown, obtained from the second level MFX analysis and thresholded at $p<0.05$. This contrastyields virtually the same activations as obtained by computing main contrast 3 as shown in Figure 7 [shift left/right vs stay left/right]. Coronal slices are shown with respect to the anterior commissure of RM112 in F99 space.

tested those ROIs that were present in both the MFX $(p=0.01)$ and FFX analysis (FWE corrected for multiple comparisons at $p=0.05$ ), as listed in Table 6 (see Materials and Methods). From these shift-sensitive ROIs, all lateral prefrontal ROIs, such as left area 12 , right area $11 / 12$, and left/right areas 46 , showed a main effect of left versus right attention $\left(F_{(1,206)}=19.94, F_{(1,206)}=\right.$ 68.84 , both $p \ll 0.0001$ and $F_{(1,206)}=30.13, F_{(1,206)}=6.18$, both $p<0.02$, respectively; Figure 10, orange box), in addition to a main effect of shifting. This was also the case for left and right caudo-medial-occipital cortex $\left(F_{(1,206)}=4.96\right.$ and $F_{(1,206)}=5.81$, both $p<0.05$ ), but as opposed to the lateral prefrontal areas, this was driven by the ipsilateral direction of attention (Fig. 10, bar plots). The caudo-medial-occipital cortex was located in vicinity of peripheral dorsal V2, also activated for ipsilateral stay (Fig. 6, \#8). Additionally, right areas 12 and 46 also showed a significant interaction $\left(F_{(1,206)}=26.39, \mathrm{p} \ll 0.0001\right.$ and $F_{(1,206)}=6.08, p<$ 0.02 ). The other ROIs, as listed in Figure 10 (yellow box), showed a main effect of shifting only and were thus shift-selective. Second, to test for direction selectivity of the shift-signal only, we performed post hoc tests within all shift ROIs (Fisher's least significant difference, comparing shift left vs shift right). This re- vealed that only left area $12(p<0.001)$, right area $12(p<0.01)$, and left area $46(p<0.05)$ showed a direction-selective shift signal, but none of the other ROIs. Example raw time courses of shift-sensitive ROIs that are not shift-selective are listed in Figure 11, whereas examples of shift-selective ROIs without a significant main effect of left versus right attention are shown in Figure 12. These included, for example, bilateral posterior medial parietal cortex, including areas V6/V6A, and MIP, but also the TPOC, ACC, the left aPCS corresponding to the rostrolateral border of area 46, and right area F6.

\section{Summary: shifting compared with contralateral stay}

Figure 13 summarizes the spatial relationships between areas showing contralateral stay activity (blue represents stay-right, left hemisphere; red represents stay-left, right hemisphere) and regions showing shift signals without (yellow represents shift only) and with a direction-selective attention component (orange represents shift together with left vs right attention). Because of the more stringent criteria applied here, a few small shift-sensitive ROIs that survived the $p<0.01$ criteria in the MFX-based analysis (Fig. 7; e.g., LIP, PE, right TPOC, and bilateral insula) disap- 

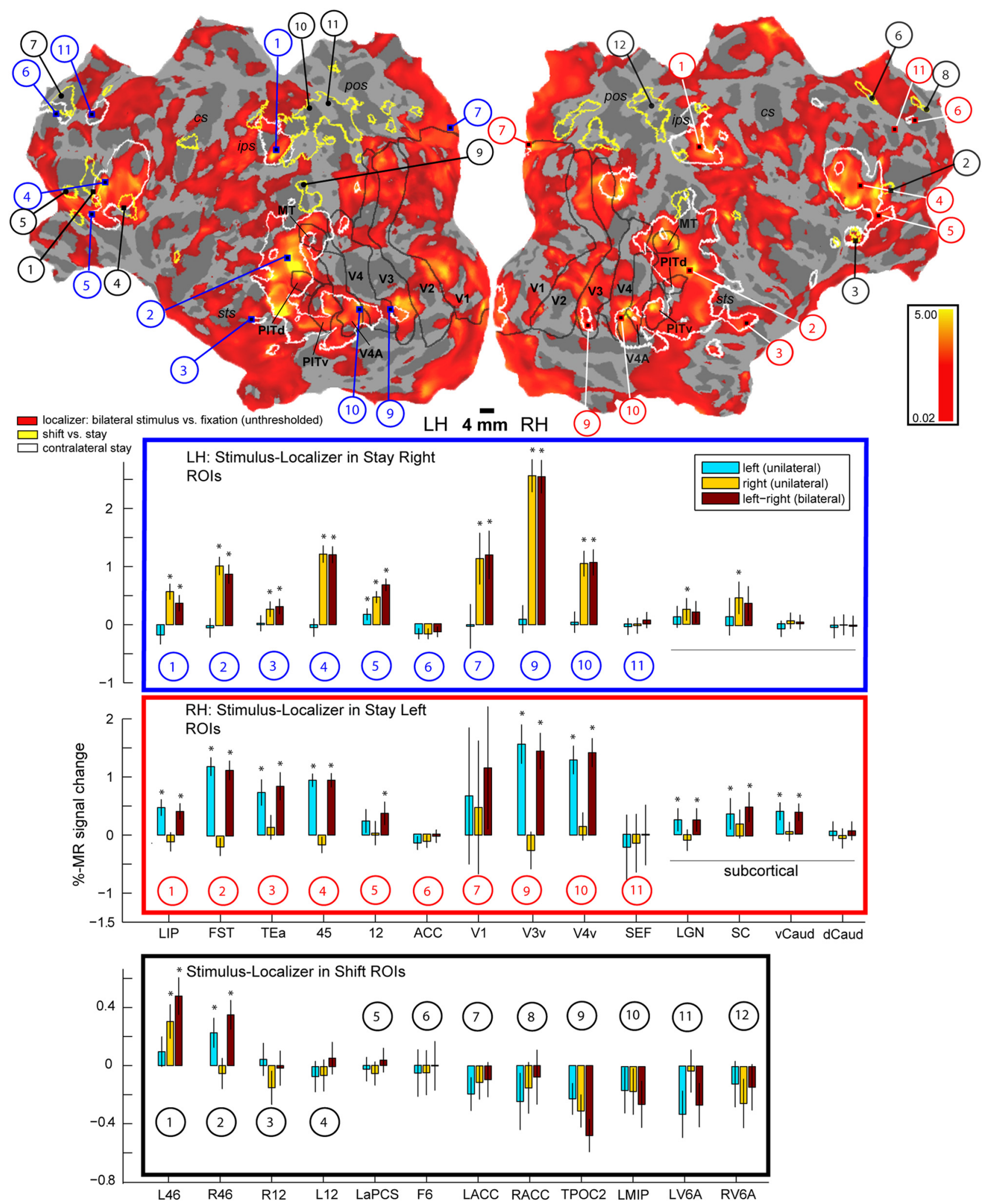

Figure 9. Segregation of shift signals compared with stay and stimulus representation signals. Top, FreeSurfer F99 inflated and flattened surfaces (LH, left hemisphere; RH, right hemisphere), displaying activation of the stimulus representation (from separate localizer experiment) obtained with the same contrast as in Figures 3 and 7 (green), but at virtually unthresholded level (hot color, $t \geq 0.02$ ). The majority of areas activated by contralateral attention (white outlines, same as hot color in Fig. 3) overlaps with the stimulus representation, opposed to areas modulated by attention shifts (yellow outlines, same as hot color in Fig. 7), clustering outside the activated areas. Black outlines indicate the same as white outlines of retinotopic areas in Figures 3 and 7. Blue panel, PSC of localizer data within the stay-right selective ROls in the left hemisphere. Red panel, PSC of localizer data within stay-left selective ROls in the right hemisphere (same ROls/numbers as in Figs. 3, 4, 5, 6). The stimulus is represented in all areas driven by contralateral attention, except in the ACC and SEF/F7 and the caudate nucleus, and much less so in subcortical areas. ${ }^{*} p<0.05$ ( $t$ test, Bonferroni corrected for $n=14$ ). Black panel, Shift-selective areas (same ROls/numbers as in Figs. 7, 11, 12) are not driven by the stimulus localizer, except for left and right areas $46 .{ }^{*} p<0.05$ ( $t$ test, Bonferroni corrected for $\left.n=12\right)$. Bar plots represent conditions of the stimulus localizer experiment: (1) left unilateral, (2) right unilateral, and (3) bilateral stimulus display versus fixation (see Materials and Methods). 


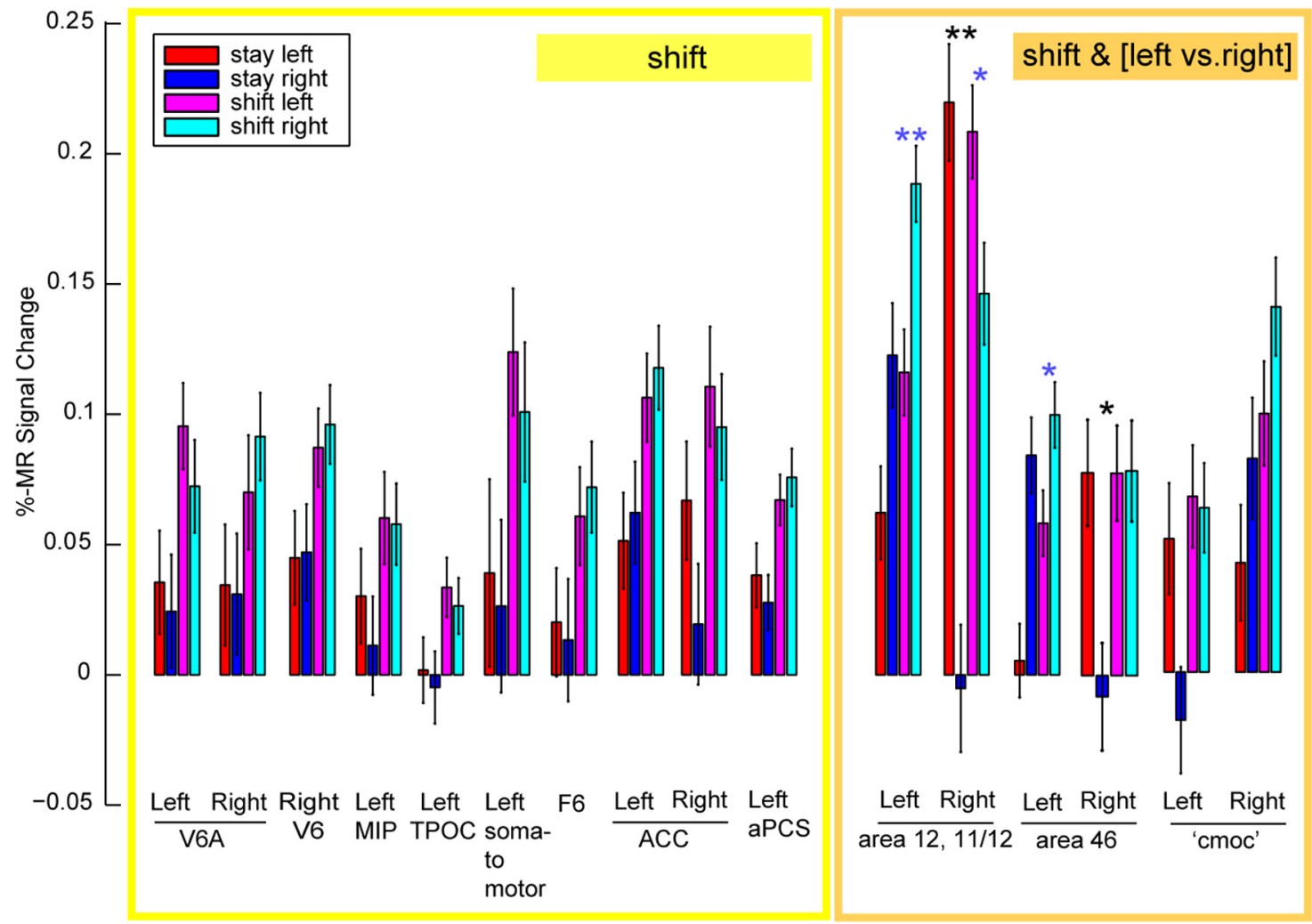

Figure 10. PSC in the shift-selective and -sensitive ROIs. Results of Table 6 (two-way ANOVA) are visualized for shift-selective ROIs showing a main effect of shifting (yellow box) compared with the shift-sensitive ROls, which also show a main effect of left versus right attention (orange box). Black stars represent the interaction for right areas 11/12 and 46. Blue stars represent a direction-selective shift signal as obtained from post hoc tests (Fisher's least significant difference). ${ }^{*} p<0.05$. ${ }^{* *} p<0.001$. cmoc, Caudo-medial-occipital cortex.

peared in Figure 13, which is a combined summary of the MFX map with the data of the two-way ANOVA based on the FFX analysis (Table 6). In general, a much larger cortical territory was modulated by stay compared with shift activity. The only position where shift signals were not adjacent to or overlapping with stay signals was in posterior medial parietal cortex. To estimate the regional distribution of cortical shift signals, we computed the number of voxels from contrast 3 that showed a main effect for shifting and no direction-selective attention signal (Fig. 13, yellow shift-selective voxels; see also Table 6). This analysis confirmed that the majority of these shift-selective voxels $(63 \%)$ were found in posterior medial parietal cortex (Fig. 13, yellow within red half-circle).

Outside posterior medial parietal cortex, shift activations were typically adjacent to stay-selective voxels (with right F6 and left CS as the only exception). For example, the shift activations in left F6 neighbored stay selectivity in F7 of the left hemisphere. Areas TPOC, ACC, areas 12 and 11/12-border, and area 46 also showed adjacent or overlapping stay- and shift-sensitive activity (Fig. 13). This suggests functional heterogeneity of these areas. Furthermore, a gradual transition existed from stay to more shift-related activity along a caudorostral axis in left area 46, which is most likely a consequence of the heterogeneous connectivity of this region (Gerbella et al., 2013).

\section{Discussion}

We recorded fMRI activity while monkeys performed covert shifts of spatial attention compared with a sustained attention baseline. We found the most extensive shift-selective signals in posterior medial parietal cortex, including the posterior portion of the fundus of the IPS, extending medially into MIP and the parieto-occiptial sulcus comprising V6 and V6A (Figs. 12, 13). The rostrolateral border of area 46, ACC, somatomotor cortex,
F6, and the most posterior tip of the STS (TPOC) also contained regions showing shift signals, not coding direction-selective attention signals (Figs. 12, 13, yellow). Furthermore, functionally more heterogeneous areas 46, 11, 12, and ACC contained subregions sensitive to either shifts or contralateral attention. Unlike most areas modulated by contralateral attention (Fig. 3), regions showing shift signals were not activated by the visual stimulus representation, suggesting that they form a distinct functional network, most likely from a higher-order nature (Figs. 7, 9). Area TPOC is remote from monkey's posterior medial parietal cortex and therefore considered an unlikely potential homolog of human SPL. It may correspond topologically to a human region near the temporoparietal junction (Corbetta et al., 2000).

Because the most extensive shift signal was located in posterior medial parietal cortical areas V6/V6A and MIP, where no stay activity was found, and because of its topographic location, we propose this region as the functional counterpart of human SPL, which is also activated by shifts of spatial attention.

\section{Comparison of monkey and human cortical areas showing attentional shift signals \\ Parietal lobe}

Several human fMRI studies, one using an experimental paradigm virtually identical to the present study, revealed signals coding spatial attention shifts in medial SPL regardless of the shift direction (Yantis et al., 2002; Molenberghs et al., 2007). Furthermore, the same region was also engaged when human subjects shifted attention between object (Serences et al., 2004), features, and task rules (Shomstein and Yantis, 2004; Chiu and Yantis, 2009; Shulman et al., 2009). Exactly as in the present monkey study, areas showing shift-related signals in humans were largely 


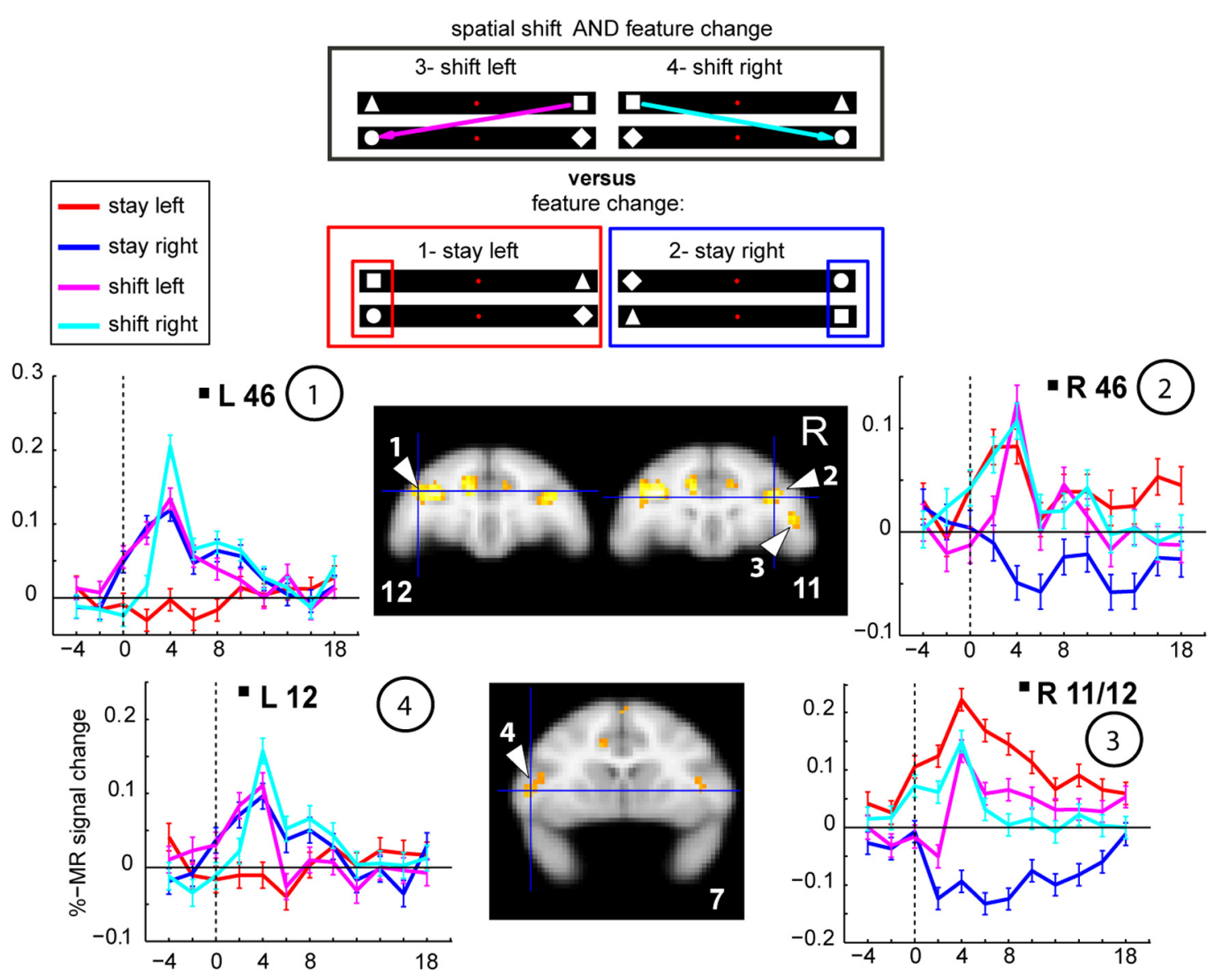

Figure 11. Raw time courses of shift-sensitive ROIs (main effect shift and left vs right attention). MFX contrast 3 (shift left and shift right vs stay left and stay right, $p=0.01$ ), luster extent threshold of 10 voxels, projected onto the freesurfer F99-monkey anatomical volume. Numbers within the circles indicate ROI locations on the flatmap in Figures 7 and 9 . Error bars indicate the trial-wise SEM.

segregated from those maintaining the current locus of attention (Yantis et al., 2002; Vandenberghe and Gillebert, 2009). In addition, Simon et al. (2002) showed systematic activations of the SPL, using four different spatially specific visuomotor tasks, including covert shifts of attention, voluntary saccades, and spatially specific grasping and pointing. The computation of attention shifts is most likely the common feature of these tasks. Causal evidence for SPL playing a functional role in attentional shifting was provided by Ciavarro et al. (2013). They applied rTMS to posterior medial SPL, which they termed putative human V6A, and observed prolonged reaction times during reorienting trials in the context of a spatial attention and a spatially selective reaching task. Corroborating causal evidence comes from another recent TMS study showing that the medial SPL is involved in shifts of attention regardless of the current locus of attention (Capotosto et al., 2013). In sharp contrast to shift activity, which was confined to SPL, modulation of fMRI activity by contralateral spatial attention signals was observed in the posterior IPS and extrastriate human visual cortex (Yantis et al., 2002; Molenberghs et al., 2008; Shulman et al., 2009; Vandenberghe et al., 2012). This was also confirmed causally by rTMS of the IPS (Capotosto et al., 2013). This study showed impairment of target discriminations largely limited to the contralateral hemifield indicating that the IPS signals the current locus of attention. Thus, in human parietal cortex, SPL encodes attentional shifts, whereas activity in posterior IPS is modulated by sustained attention signals.

In the present monkey study, sustained contralateral attention also activated the IPS (LIP) while posterior medial parietal cortex was activated by shifts of attention. The former result is consistent with a lesion study showing impaired performance during the detection of contralateral targets in the context of a conjunction search task (Wardak et al., 2004). Thus, as in humans, different subregions of monkey parietal cortex are involved in different aspects of the control of spatial attention, such as sustained contralateral attention, versus spatial-attentional shifting. Monkey V6A receives most of its visual inputs via area V6 (Galletti et al., 2001; Passarelli et al., 2011), and it contains neurons showing attention, saccade, reach, and grasping-related activity (Galletti et al., 1996, 1999, 2010; Kutz et al., 2003; Fattori et al., 2004, 2005; Premereur et al., 2015). Areas V6A and MIP in macaque form a tightly linked complex where visual, somatic, and motor information is integrated (Passarelli et al., 2011). This matches the functional characteristics of human SPL and distinguishes V6A/MIP-complex from areas simply responsive to visual stimulation (Galletti et al., 2010) or modulated by sustained attention (Fig. 9). More generally, the present results suggest that the functional architecture of monkey and human SPL may be more similar than initially proposed (Grefkes and Fink, 2005; Margulies et al., 2009; Vanduffel et al., 2014). Indeed, several authors (Vandenberghe et al., 2001; Simon et al., 2002; Galletti et al., 2010) suggested tentatively that human SPL might be homologous to monkey area V6A. In humans, SPL has been hypothesized to be the source of attentional modulation, whereas extrastriate areas have been called the sites of attentional modulation (Yantis et al., 2002). Possibly, the monkey V6A/MIP complex similarly exerts higher-order control over extrastriate cortex, 

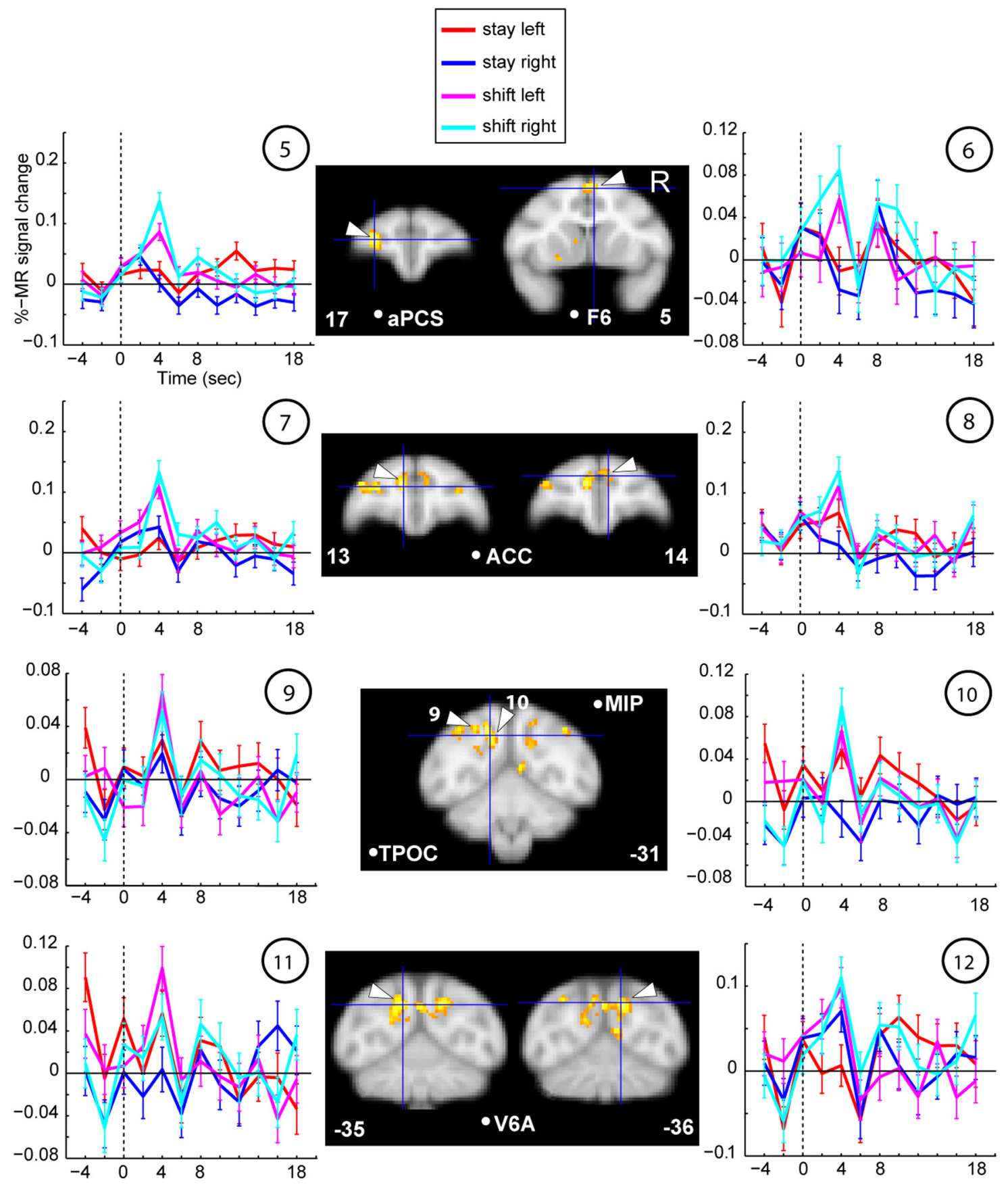

Figure 12. Raw time courses of shift-selective ROls (main effect of shift only). Same conventions as in Figure 11.

but this requires further study (e.g., by means of effective connectivity analysis) (Ekstrom et al., 2008; Friston, 2011).

\section{Frontal cortex}

Despite commonalities between human and monkey parietal cortex in present and previous studies focusing on attention shifts, differences were observed in frontal cortex. For example, shift-sensitive fMRI activations were observed in several frontal areas of monkeys but not humans (Molenberghs et al., 2007).

Specifically, shift signals were observed in frontal areas 46, $11 / 12$, ACC, and pre-SMA/F6. A potential explanation for the apparent discrepancy between human and monkey studies may lie in the presence and absence of feedback signals, respectively. In monkeys, ACC is involved in computing context-dependent error likelihoods by integrating feedback signals (Kuwabara et al., 2014). Whereas reward contingencies have been shown to be represented independently of spatial attention shifts within human medial parietal cortex (Tosoni et al., 2013), no such evidence exists for monkey parietal cortex.

Another explanation may be that endogenously driven shifts in attention may require relatively more cognitive control for monkeys than for humans, explaining the stronger activation of monkey PFC. Corroborating evidence that task demand may be a critical factor regarding the contribution of frontal cortex comes from a human study directly comparing shifts between task rules and spatial-attention shifts within the same task (Chiu and Yantis, 2009). Unlike Molenberghs et al. (2007), these authors ob- 


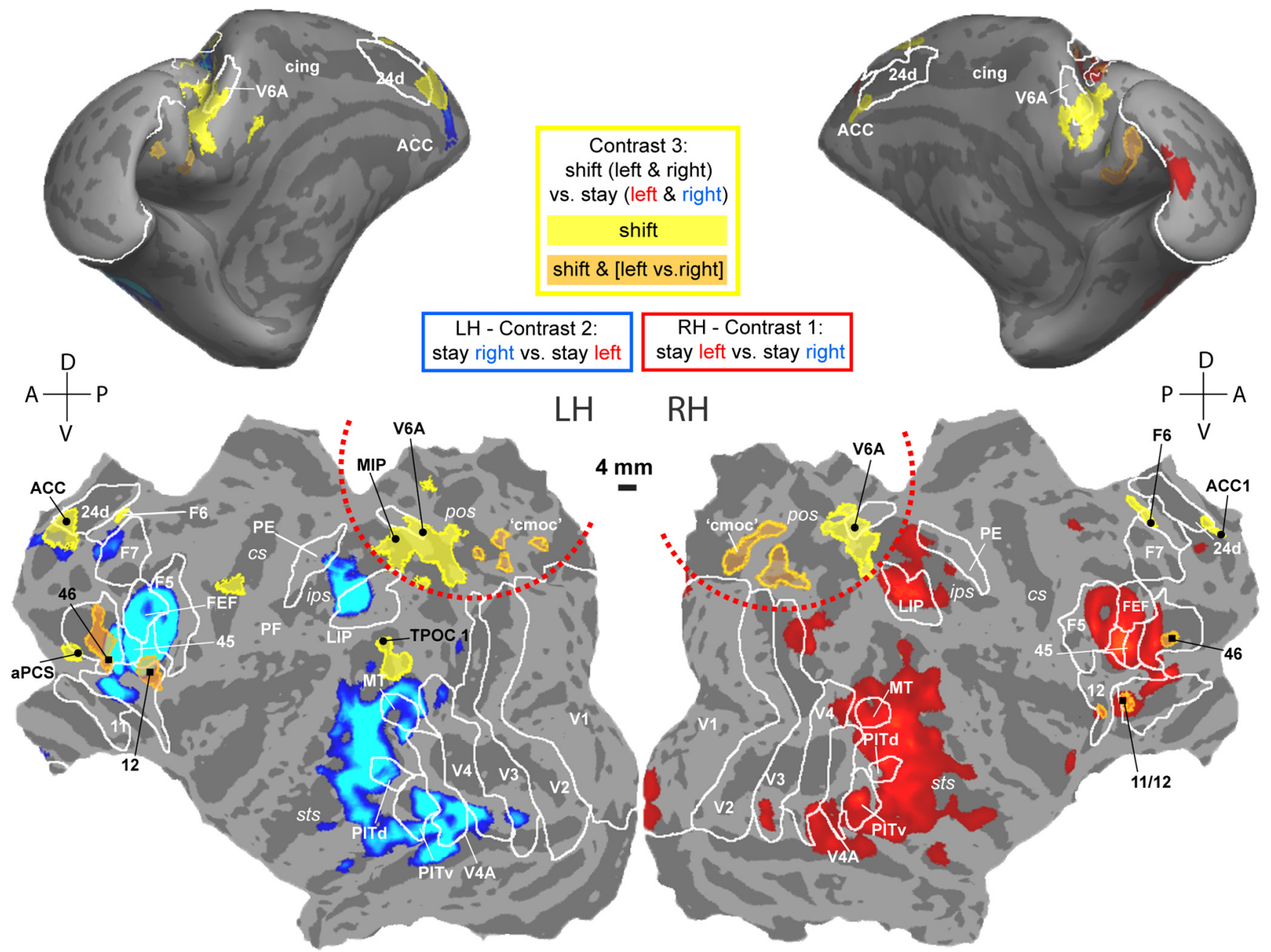

Figure 13. Spatial comparison between cortical stay and shift signals. FreeSurfer F99 inflated (top) and flattened (bottom) surfaces. Only those shift ROls from Figure 7 are plotted that show a significant main effect (two-way ANOVA, shift/stay and left/right) according to Table 6 and Figure 10. Yellow represents shift-selective ROls, without a main effect of left versus right attention. Orange represents shift-sensitive ROIs, displaying a main effect of left versus right attention. Contralateral stay (blue/red, same as in Fig. 3), left hemisphere (LH), contrast 2 (blue), and right hemisphere (RH), contrast 1 (red). Red dotted lines indicate medial occipitoparietal cortex: shift activations not overlapping with the stay activations. For all labels/R0ls, same conventions as in Figures 3, 7, and 9. cmoc, Caudo-medial-occipital cortex.

served, in addition to SPL, precentral and frontal activations when human subjects had to shift between different task sets in addition to spatial shifts in attention, thus requiring higher levels of cognitive control. In their comparative fMRI study, Nakahara et al. (2002) also showed activations in ventral orbitofrontal area 12 when humans and monkeys had to switch task sets during a cognitively demanding Wisconsin Card Sorting task. In our study, area 12 was activated during spatial attention shifts as well as stay-trials, corroborating its role in cognitive control. Finally, it is worth noting that a previous comparative fMRI study reported much stronger and widespread activations in monkey PFC compared with that of humans when subjects simply had to fixate to images of objects versus scrambled images (Denys et al., 2004).

\section{Shifts of attention or response preparation in posterior medial parietal cortex?}

Area MIP is part of the parietal "reaching" region (Cohen and Andersen, 2002), which also includes other areas, such as V6A and the intraparietal parts of area PE. Furthermore, it has been claimed that MIP neurons are involved in processing visuospatial transformations (Cohen and Andersen, 2002), even before a movement is initiated (Johnson et al., 1996). Hence, one could argue that the shift-selective activations observed in MIP and V6A are linked with preparatory motor activity in the monkey. We think this is an unlikely explanation for our results because dimming events were matched between stay and shift trials, between left and right hemifield, and across relevant and irrelevant shapes. Monkeys were trained to respond to dimming events occurring independently of shift events. Any response-preparatory activity should thus be equally distributed across event types; hence, this cannot explain the observed shift signals in medial parietal cortex.

Monkey V6A contains visual, somatic, oculomotor, and reaching neurons (Battaglia-Mayer et al., 2001; Gamberini et al., 2009). Consistent with our results, Galletti et al. (2010) showed that V6A neurons fire during covert shifts of attention, with equal numbers of cells tuned for contralateral and ipsilateral shifts. Compared with previous human and monkey studies, we attempted to match all sensory events as well as possible, measured eye and hand positions, and dissociated these potential confounds from the events of interest (shift/stay). Nonetheless, we observed shift-selective activations in this region of posterior medial parietal cortex, indicating that also in monkey, there may exist a region that is responsible for shifts of attention in different modalities. 
In conclusion, in monkeys as in humans (Molenberghs et al., 2007), posterior medial parietal cortex is involved in shifting spatial attention in the absence of overt behavior. Our results suggest that monkey posterior medial parietal cortex is functionally homologous to a topographically corresponding portion in the human (SPL). Hence, we posit, that, in addition to the established role of this part of the cortex in directed hand and arm movements (and to a lesser extent also eye movements), it serves as a key area for shifting spatial attention. In the monkey, additional frontal areas are recruited during attention shifts, complying with the higher cognitive demands required for the computation of attention shifts, relative to humans. Also, in correspondence with human IPS, its monkey counterpart, and particularly LIP, may be instrumental in coding the location and significance of a stimulus, as others have suggested (Gottlieb and Goldberg, 1999; Wardak et al., 2002; Bisley and Goldberg, 2003b; Molenberghs et al., 2007).

The identification of a likely functional homology between human SPL and monkey posterior medial parietal cortex invites investigation into the neuronal mechanisms underlying attentional shifting using functional connectivity analyses, electrophysiological recordings, and the most refined causal methods in an animal model closely akin to humans (Vanduffel et al., 2014).

\section{References}

Arsenault JT, Nelissen K, Jarraya B, Vanduffel W (2013) Dopaminergic reward signals selectively decrease fMRI activity in primate visual cortex. Neuron 77:1174-1186. CrossRef Medline

Battaglia-Mayer A, Ferraina S, Genovesio A, Marconi B, Squatrito S, Molinari M, Lacquaniti F, Caminiti R (2001) Eye-hand coordination during reaching: II. An analysis of the relationships between visuomanual signals in parietal cortex and parieto-frontal association projections. Cereb Cortex 11:528-544. CrossRef Medline

Bisley JW, Goldberg ME (2003a) Neuronal activity in the lateral intraparietal area and spatial attention. Science 299:81-86. CrossRef Medline

Bisley JW, Goldberg ME (2003b) The role of the parietal cortex in the neural processing of saccadic eye movements. Adv Neurol 93:141-157. Medline

Buschman TJ, Miller EK (2009) Serial, covert shifts of attention during visual search are reflected by the frontal eye fields and correlated with population oscillations. Neuron 63:386-396. CrossRef Medline

Capotosto P, Tosoni A, Spadone S, Sestieri C, Perrucci MG, Romani GL, Della Penna S, Corbetta M (2013) Anatomical segregation of visual selection mechanisms in human parietal cortex. J Neurosci 33:6225-6229. CrossRef Medline

Chiu YC, Yantis S (2009) A domain-independent source of cognitive control for task sets: shifting spatial attention and switching categorization rules. J Neurosci 29:3930-3938. CrossRef Medline

Ciavarro M, Ambrosini E, Tosoni A, Committeri G, Fattori P, Galletti C (2013) rTMS of medial parieto-occipital cortex interferes with attentional reorienting during attention and reaching tasks. J Cogn Neurosci 25:1453-1462. CrossRef Medline

Cohen YE, Andersen RA (2002) A common reference frame for movement plans in the posterior parietal cortex. Nat Rev Neurosci 3:553-562. CrossRef Medline

Corbetta M, Kincade JM, Ollinger JM, McAvoy MP, Shulman GL (2000) Voluntary orienting is dissociated from target detection in human posterior parietal cortex. Nat Neurosci 3:292-297. CrossRef Medline

Cui X, Stetson C, Montague PR, Eagleman DM (2009) Ready.go: amplitude of the FMRI signal encodes expectation of cue arrival time 1. PLoS Biol 7:e1000167. CrossRef Medline

Denys K, Vanduffel W, Fize D, Nelissen K, Sawamura H, Georgieva S, Vogels R, Van Essen D, Orban GA (2004) Visual activation in prefrontal cortex is stronger in monkeys than in humans. J Cogn Neurosci 16:1505-1516. CrossRef Medline

Ekstrom LB, Roelfsema PR, Arsenault JT, Bonmassar G, Vanduffel W (2008) Bottom-up dependent gating of frontal signals in early visual cortex. Science 321:414-417. CrossRef Medline

Ekstrom LB, Roelfsema PR, Arsenault JT, Kolster H, Vanduffel W (2009) Modulation of the contrast response function by electrical microstimula- tion of the macaque frontal eye field. J Neurosci 29:10683-10694. CrossRef Medline

Engbert R, Kliegl R (2003) Microsaccades uncover the orientation of covert attention. Vision Res 43:1035-1045. CrossRef Medline

Esterman M, Chiu YC, Tamber-Rosenau BJ, Yantis S (2009) Decoding cognitive control in human parietal cortex. Proc Natl Acad Sci U S A 106: 17974-17979. CrossRef Medline

Fattori P, Breveglieri R, Amoroso K, Galletti C (2004) Evidence for both reaching and grasping activity in the medial parieto-occipital cortex of the macaque 47. Eur J Neurosci 20:2457-2466. CrossRef Medline

Fattori P, Kutz DF, Breveglieri R, Marzocchi N, Galletti C (2005) Spatial tuning of reaching activity in the medial parieto-occipital cortex (area V6A) of macaque monkey 42. Eur J Neurosci 22:956-972. CrossRef Medline

Friston KJ (2011) Functional and effective connectivity: a review. Brain Connect 1:13-36. CrossRef Medline

Friston KJ, Stephan KE, Lund TE, Morcom A, Kiebel S (2005) Mixed-effects and fMRI studies. Neuroimage 24:244-252. CrossRef Medline

Galletti C, Fattori P, Battaglini PP, Shipp S, Zeki S (1996) Functional demarcation of a border between areas V6 and V6A in the superior parietal gyrus of the macaque monkey. Eur J Neurosci 8:30-52. CrossRef Medline

Galletti C, Fattori P, Kutz DF, Gamberini M (1999) Brain location and visual topography of cortical area V6A in the macaque monkey 59. Eur J Neurosci 11:575-582. CrossRef Medline

Galletti C, Gamberini M, Kutz DF, Fattori P, Luppino G, Matelli M (2001) The cortical connections of area V6: an occipito-parietal network processing visual information 56. Eur J Neurosci 13:1572-1588. CrossRef Medline

Galletti C, Breveglieri R, Lappe M, Bosco A, Ciavarro M, Fattori P (2010) Covert shift of attention modulates the ongoing neural activity in a reaching area of the macaque dorsomedial visual stream. PLoS One 5:e15078. CrossRef Medline

Gamberini M, Passarelli L, Fattori P, Zucchelli M, Bakola S, Luppino G, Galletti C (2009) Cortical connections of the visuomotor parietooccipital area V6Ad of the macaque monkey. J Comp Neurol 513:622-642. CrossRef Medline

Gerbella M, Borra E, Tonelli S, Rozzi S, Luppino G (2013) Connectional heterogeneity of the ventral part of the macaque area 46 . Cereb Cortex 23:967-987. CrossRef Medline

Gottlieb J, Goldberg ME (1999) Activity of neurons in the lateral intraparietal area of the monkey during an antisaccade task. Nat Neurosci 2:906912. CrossRef Medline

Grefkes C, Fink GR (2005) The functional organization of the intraparietal sulcus in humans and monkeys. J Anat 207:3-17. CrossRef Medline

Janssens T, Keil B, Farivar R, McNab JA, Polimeni JR, Gerits A, Arsenault JT, Wald LL, Vanduffel W (2012) An implanted 8-channel array coil for high-resolution macaque MRI at 3T. Neuroimage 62:1529-1536. CrossRef Medline

Janssens T, Zhu Q, Popivanov ID, Vanduffel W (2014) Probabilistic and single-subject retinotopic maps reveal the topographic organization of face patches in the macaque cortex. J Neurosci 34:10156-10167. CrossRef Medline

Johnson PB, Ferraina S, Bianchi L, Caminiti R (1996) Cortical networks for visual reaching: physiological and anatomical organization of frontal and parietal lobe arm regions. Cereb Cortex 6:102-119. CrossRef Medline

Kagan I, Iyer A, Lindner A, Andersen RA (2010) Space representation for eye movements is more contralateral in monkeys than in humans. Proc Natl Acad Sci U S A 107:7933-7938. CrossRef Medline

Kaping D, Vinck M, Hutchison RM, Everling S, Womelsdorf T (2011) Specific contributions of ventromedial, anterior cingulate, and lateral prefrontal cortex for attentional selection and stimulus valuation. PLoS Biol 9:e1001224. CrossRef Medline

Kastner S, Ungerleider LG (2000) Mechanisms of visual attention in the human cortex. Annu Rev Neurosci 23:315-341. CrossRef Medline

Kelley TA, Serences JT, Giesbrecht B, Yantis S (2008) Cortical mechanisms for shifting and holding visuospatial attention. Cereb Cortex 18:114-125. CrossRef Medline

Kolster H, Mandeville JB, Arsenault JT, Ekstrom LB, Wald LL, Vanduffel W (2009) Visual field map clusters in macaque extrastriate visual cortex. J Neurosci 29:7031-7039. CrossRef Medline

Kutz DF, Fattori P, Gamberini M, Breveglieri R, Galletti C (2003) Early-and 
late-responding cells to saccadic eye movements in the cortical area V6A of macaque monkey 51. Exp Brain Res 149:83-95. Medline

Kuwabara M, Mansouri FA, Buckley MJ, Tanaka K (2014) Cognitive control functions of anterior cingulate cortex in macaque monkeys performing a Wisconsin Card Sorting Test analog. J Neurosci 34:7531-7547. CrossRef Medline

Latto R, Cowey A (1971) Visual field defects after frontal eye-field lesions in monkeys. Brain Res 30:1-24. CrossRef Medline

Laubrock J, Engbert R, Kliegl R (2005) Microsaccade dynamics during covert attention. Vision Res 45:721-730. CrossRef Medline

Leite FP, Tsao D, Vanduffel W, Fize D, Sasaki Y, Wald LL, Dale AM, Kwong KK, Orban GA, Rosen BR, Tootell RB, Mandeville JB (2002) Repeated fMRI using iron oxide contrast agent in awake, behaving macaques at 3 Tesla. Neuroimage 16:283-294. CrossRef Medline

Lewis JW, Van Essen DC (2000a) Corticocortical connections of visual, sensorimotor, and multimodal processing areas in the parietal lobe of the macaque monkey. J Comp Neurol 428:112-137. CrossRef Medline

Lewis JW, Van Essen DC (2000b) Mapping of architectonic subdivisions in the macaque monkey, with emphasis on parieto-occipital cortex. J Comp Neurol 428:79-111. CrossRef Medline

Li CS, Mazzoni P, Andersen RA (1999) Effect of reversible inactivation of macaque lateral intraparietal area on visual and memory saccades. J Neurophysiol 81:1827-1838. Medline

Liu T, Slotnick SD, Serences JT, Yantis S (2003) Cortical mechanisms of feature-based attentional control. Cereb Cortex 13:1334-1343. CrossRef Medline

Madore B, Glover GH, Pelc NJ (1999) Unaliasing by Fourier-encoding the overlaps using the temporal dimension (UNFOLD), applied to cardiac imaging and fMRI. Magn Reson Med 42:813-828. CrossRef Medline

Mandeville JB, Marota JJ (1999) Vascular filters of functional MRI: spatial localization using BOLD and CBV contrast. Magn Reson Med 42:591598. CrossRef Medline

Margulies DS, Vincent JL, Kelly C, Lohmann G, Uddin LQ, Biswal BB, Villringer A, Castellanos FX, Milham MP, Petrides M (2009) Precuneus shares intrinsic functional architecture in humans and monkeys. Proc Natl Acad Sci U S A 106:20069-20074. CrossRef Medline

McLaren DG, Kosmatka KJ, Oakes TR, Kroenke CD, Kohama SG, Matochik JA, Ingram DK, Johnson SC (2009) A population-average MRI-based atlas collection of the rhesus macaque. Neuroimage 45:52-59. CrossRef Medline

Molenberghs P, Mesulam MM, Peeters R, Vandenberghe RR (2007) Remapping attentional priorities: differential contribution of superior parietal lobule and intraparietal sulcus. Cereb Cortex 17:2703-2712. CrossRef Medline

Molenberghs P, Gillebert CR, Peeters R, Vandenberghe R (2008) Convergence between lesion-symptom mapping and functional magnetic resonance imaging of spatially selective attention in the intact brain. J Neurosci 28:3359-3373. CrossRef Medline

Nakahara K, Hayashi T, Konishi S, Miyashita Y (2002) Functional MRI of macaque monkeys performing a cognitive set-shifting task. Science 295: 1532-1536. CrossRef Medline

Nelissen K, Luppino G, Vanduffel W, Rizzolatti G, Orban GA (2005) Observing others: multiple action representation in the frontal lobe. Science 310:332-336. CrossRef Medline

Nelissen K, Borra E, Gerbella M, Rozzi S, Luppino G, Vanduffel W, Rizzolatti G, Orban GA (2011) Action observation circuits in the macaque monkey cortex. J Neurosci 31:3743-3756. CrossRef Medline

Passarelli L, Rosa MG, Gamberini M, Bakola S, Burman KJ, Fattori P, Galletti C (2011) Cortical connections of area V6Av in the macaque: a visualinput node to the eye/hand coordination system 17. J Neurosci 31:17901801. CrossRef Medline

Patel GH, Shulman GL, Baker JT, Akbudak E, Snyder AZ, Snyder LH, Corbetta M (2010) Topographic organization of macaque area LIP. Proc Natl Acad Sci U S A 107:4728-4733. CrossRef Medline

Paxinos G, Huang XF, Petrides M, Toga A (2008) The Rhesus monkey brain: in stereotaxic coordinates. London: Elsevier.
Premereur E, Janssen P, Vanduffel W (2015) Effector specificity in macaque frontal and parietal cortex. J Neurosci 35:3446-3459. CrossRef Medline

Pruessmann KP, Weiger M, Scheidegger MB, Boesiger P (1999) SENSE: sensitivity encoding for fast MRI. Magn Reson Med 42:952-962. CrossRef Medline

Serences JT, Schwarzbach J, Courtney SM, Golay X, Yantis S (2004) Control of object-based attention in human cortex. Cereb Cortex 14:1346-1357. CrossRef Medline

Shomstein S, Yantis S (2004) Control of attention shifts between vision and audition in human cortex. J Neurosci 24:10702-10706. CrossRef Medline

Shulman GL, Astafiev SV, Franke D, Pope DL, Snyder AZ, McAvoy MP, Corbetta M (2009) Interaction of stimulus-driven reorienting and expectation in ventral and dorsal frontoparietal and basal ganglia-cortical networks. J Neurosci 29:4392-4407. CrossRef Medline

Simon O, Mangin JF, Cohen L, Le Bihan D, Dehaene S (2002) Topographical layout of hand, eye, calculation, and language-related areas in the human parietal lobe. Neuron 33:475-487. CrossRef Medline

Thompson KG, Bichot NP, Schall JD (1997) Dissociation of visual discrimination from saccade programming in macaque frontal eye field. J Neurophysiol 77:1046-1050. Medline

Tosoni A, Shulman GL, Pope AL, McAvoy MP, Corbetta M (2013) Distinct representations for shifts of spatial attention and changes of reward contingencies in the human brain. Cortex 49:1733-1749. CrossRef Medline

Van Essen DC (2004) Surface-based approaches to spatial localization and registration in primate cerebral cortex. Neuroimage 23 [Suppl 1]:S97-S107.

Van Essen DC, Drury HA, Dickson J, Harwell J, Hanlon D, Anderson CH (2001) An integrated software suite for surface-based analyses of cerebral cortex. J Am Medical Inform Assoc 8:443-459. CrossRef Medline

Vandenberghe R, Gillebert CR (2009) Parcellation of parietal cortex: convergence between lesion-symptom mapping and mapping of the intact functioning brain. Behav Brain Res 199:171-182. CrossRef Medline

Vandenberghe R, Gitelman DR, Parrish TB, Mesulam MM (2001) Functional specificity of superior parietal mediation of spatial shifting. Neuroimage 14:661-673. CrossRef Medline

Vandenberghe R, Molenberghs P, Gillebert CR (2012) Spatial attention deficits in humans: the critical role of superior compared to inferior parietal lesions. Neuropsychologia 50:1092-1103. CrossRef Medline

Vanduffel W, Fize D, Mandeville JB, Nelissen K, Van Hecke P, Rosen BR, Tootell RB, Orban GA (2001) Visual motion processing investigated using contrast agent-enhanced fMRI in awake behaving monkeys. Neuron 32:565-577. CrossRef Medline

Vanduffel W, Zhu Q, Orban GA (2014) Monkey cortex through fMRI glasses. Neuron 83:533-550. CrossRef Medline

Wardak C, Olivier E, Duhamel JR (2002) Saccadic target selection deficits after lateral intraparietal area inactivation in monkeys. J Neurosci 22: 9877-9884. Medline

Wardak C, Olivier E, Duhamel JR (2004) A deficit in covert attention after parietal cortex inactivation in the monkey. Neuron 42:501-508. CrossRef Medline

Wardak C, Ibos G, Duhamel JR, Olivier E (2006) Contribution of the monkey frontal eye field to covert visual attention. J Neurosci 26:4228-4235. CrossRef Medline

Wardak C, Olivier E, Duhamel JR (2011) The relationship between spatial attention and saccades in the frontoparietal network of the monkey. Eur J Neurosci 33:1973-1981. CrossRef Medline

Xiao Q, Barborica A, Ferrera VP (2007) Modulation of visual responses in macaque frontal eye field during covert tracking of invisible targets. Cereb Cortex 17:918-928. CrossRef Medline

Yantis S, Schwarzbach J, Serences JT, Carlson RL, Steinmetz MA, Pekar JJ, Courtney SM (2002) Transient neural activity in human parietal cortex during spatial attention shifts. Nat Neurosci 5:995-1002. CrossRef Medline

Zhao F, Wang P, Hendrich K, Ugurbil K, Kim SG (2006) Cortical layerdependent BOLD and CBV responses measured by spin-echo and gradient-echo fMRI: insights into hemodynamic regulation. Neuroimage 30:1149-1160. CrossRef Medline 